\title{
Lessons Learned: From Dye-Sensitized Solar Cells to All-Solid-State Hybrid Devices
}

\author{
Pablo Docampo, Stefan Guldin, Tomas Leijtens, Nakita K. Noel, Ullrich Steiner,* \\ and Henry J. Snaith*
}

The field of solution-processed photovoltaic cells is currently in its second spring. The dye-sensitized solar cell is a widely studied and longstanding candidate for future energy generation. Recently, inorganic absorber-based devices have reached new record efficiencies, with the benefits of all-solidstate devices. In this rapidly changing environment, this review sheds light on recent developments in all-solid-state solar cells in terms of electrode architecture, alternative sensitizers, and hole-transporting materials. These concepts are of general applicability to many next-generation device platforms.

energy costs, which result in long financial and energy payback times. ${ }^{[6-9]}$ This has fostered the development of solutionprocessable solar cells, ${ }^{[10-13]}$ which benefit from low-cost materials, cheap, highthroughput manufacturing methods such as reel-to-reel printing, and low energy expenditure. ${ }^{[14]}$

The dye-sensitized solar cell (DSSC) has been a long-standing candidate to fulfil this long list of requirements. For the solid-state version (ssDSSC), power conversion efficiencies of over $20 \%$ have

\section{Introduction}

Modern society is facing ever growing concerns over climate change caused by the combustion of fossil fuels. ${ }^{[1-3]}$ Of the available renewable and clean energy sources, solar energy is the most abundant. In fact, coverage of less than $0.4 \%$ of the world's surface area would be sufficient to meet the world's energy needs, assuming 15\% solar energy conversion efficiency. It is therefore no surprise that there has been a recent surge in the development of photovoltaic technologies..$^{[4]}$

Photovoltaic devices based on crystalline, inorganic semiconductors have reached impressive power conversion efficiencies of over $28 \%$ in single-junction, and $37 \%$ in multi-junction device architectures under full-sun illumination. ${ }^{[5]}$ However, this class of photovoltaics suffers from its high production and

\section{P. Docampo}

Department of Chemistry

University of Munich (LMU)

Butenandtstr. 5-13 81377, Munich, Germany

S. Guldin

Institute of Materials

Ècole Polytechnique Fèdèrale de Lausanne

1015, Lausanne, Switzerland

T. Leijtens, N. K. Noel, H. J. Snaith

Department of Physics

Clarendon Laboratory

University of Oxford

Parks Road, Oxford, OX1 3PU, UK

E-mail: h.snaith1@physics.ox.ac.uk

U. Steiner

Cavendish Laboratory

Department of Physics

University of Cambridge

J. J. Thomson Avenue, Cambridge, CB3 OHE, UK

E-mail: u.steiner@phy.cam.ac.uk

DOI: 10.1002/adma.201400486 been predicted, ${ }^{[15]}$ while utilizing low-cost materials, ${ }^{[16]}$ lowtemperature processing $\left(<150{ }^{\circ} \mathrm{C}\right)$, and reel-to-reel fabrication methods. ${ }^{[17,18]}$ However, despite numerous improvements to the electron-transporting anode, the light-absorbing dyesensitizers, and the hole-transporting materials, the ssDSSC has fallen short of its potential. The best-performing SsDSSC remains at $7 \%$ power conversion efficiency. ${ }^{[19]}$ Very recently, inorganic-absorber-based sensitized architectures have reached new record conversion efficiencies of up to $15 \%{ }^{[20]}$ In this dynamically developing field, this review sheds light on recent developments in all-solid-state solar cells, discussing in particular the electrode architecture, alternative sensitizers, and hole-transporting materials that are of general applicability to many next-generation device platforms.

We will focus this discussion on understanding which components of traditional ssDSSCs limit device performance, review what has been done to address these issues, and discuss why the recent development of perovskite-sensitized solar cells appears to overcome these hurdles. We will pinpoint the key areas for future developments in both efficiency and stability of all-solid-state hybrid devices. Conclusions are applicable to a variety of next-generation device platforms, may they be composed of similar materials or have similar device architectures.

\section{DSSC and ssDSSC: Functioning and Limitations}

The absorption of light followed by the generation and transport of charge carriers to the electrodes are the principal functions of any photovoltaic cell. In conventional p-n junction-based photovoltaic devices these tasks are carried out by the same material, an inorganic semiconductor. The working principle of DSSCs is fundamentally different and takes inspiration from photosynthesis. ${ }^{[21]}$ Light absorption and charge 
generation occur separately in specifically designed device components. The light-harvesting complex is a photoactive dye molecule that is anchored to the surface of a wide bandgap semiconductor oxide and surrounded by a redox medium. Upon absorption of light, incident photons stimulate the dye molecule to form an excited state. With appropriate energylevel alignment of the components, charge separation occurs at the interface to the electron and hole conducting materials. Electrons are injected into the conduction band of an inorganic semiconductor and transported to the electrode. Regeneration of the oxidized dye takes place via an electron-donor species, typically an iodine $\left(3 \mathrm{I}^{-} / \mathrm{I}_{3}^{-}\right)$-based liquid electrolyte. Initial work dates back as early as 1887 when James Moser showed the extension of the absorption spectrum of a photoelectrochemical cell by the sensitization with a light-absorbing dye molecule. ${ }^{[22]}$ However, it wasn't until the 1960 s and $70 \mathrm{~s}$ that the first working photovoltaic devices based on dye-sensitization of wide bandgap semiconductors were constructed. [23-25] Nevertheless, the acceptance of DSSCs as a promising photovoltaic concept only arose from the seminal work of O'Regan and Grätzel who introduced a novel electrode architecture in the form of a mesoporous $\mathrm{TiO}_{2}$ film with a 780 -fold increase in surface area, which led to substantially increased dyeloading and a rise in conversion efficiency of incident photons to electrons by several orders of magnitude. ${ }^{[26]}$ The strategy of sintering nanometer-sized $\mathrm{TiO}_{2}$ particles to form an electronconducting random network with an extremely large surface area is widely used today and is a central part of a typical device architecture, shown in Figure 1.

Like any single-junction photovoltaic cell, conventional DSSCs obey the Shockley-Queisser limit for the power conversion of the sun's black body radiation, shown in Figure $1 \mathrm{~b}$. Accordingly, the ideal excitation energy, $\Delta E$, should lie around $1.1 \mathrm{eV}(\lambda \geq 1125 \mathrm{~nm})$, which would result in a power conversion efficiency of $33.7 \%$ for full conversion of the dye excitation energy into electrical energy. ${ }^{[2]}$ These values are far from present experimental realization. Historically, the ruthenium-based photosensitizers N3 (1991), ${ }^{[28]}$ N719 (1999), ${ }^{[29]}$ and the black dye N749 (2001) $)^{[30]}$ were milestones in dye synthesis and enabled power conversion efficiency records of $10.0 \%,{ }^{[28]} 10.6 \%{ }^{[31]}$ and $11.1 \%,{ }^{[32]}$ respectively. Recently, a shift from iodine to cobaltbased electrolytes together with the development of organic donor- $\pi$-acceptor porphyrin dyes enabled the benchmark to increase to $12.3 \%$. $^{[33]}$

The performance of DSSCs is largely determined by the energy-level alignment between the individual components, as well as the underlying kinetics of the charge separation and charge-transfer processes. Figure 1c shows an energylevel diagram of a conventional liquid electrolyte DSSC with the underlying reaction kinetics. The fundamental processes include:

1. Photoexcitation of the dye $\mathrm{e}^{[34]}$

2. Electron injection into the metal oxide ${ }^{[35,36]}$

3. Electron transport to the working electrode ${ }^{[37]}$

4. Regeneration of the oxidized dye by electron transfer from donor species ${ }^{[38,39]}$

5. Hole transport to the electrode ${ }^{[40]}$

6. Reduction of the oxidized donor ${ }^{[41]}$

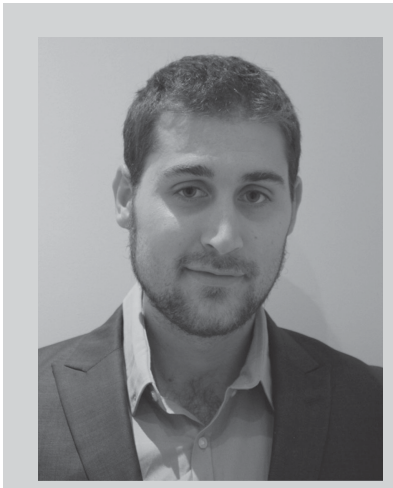

Dr. Pablo Docampo is currently a Marie Curie Fellow at the Ludwig Maximilian University of Munich. He obtained his Ph.D. from the University of Oxford in 2012 for his work on the electronic properties of metal oxides in solid-state dye-sensitized solar cells. His current research interests include novel photoactive materials and the development of organic charge extraction layers in hybrid photovoltaic applications.

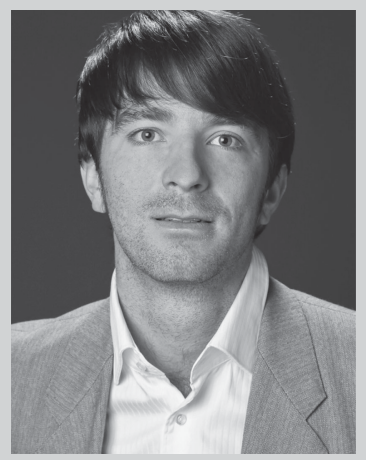

Dr. Stefan Guldin is currently a postdoctoral fellow of the German Academy of Sciences (Leopoldina) at the École Polytechnique Fédérale de Lausanne, Switzerland and will soon join University College London as a Lecturer. He obtained in 2012 a Ph.D. from the University of Cambridge for his work on "Inorganic nanoarchitectures by organic self-assembly", mainly elucidating the structure-function relationship in dye-sensitized solar cells. His research interests include the self-assembly of soft $\&$ hybrid matter, adaptive and responsive materials architectures and light-matter interaction.

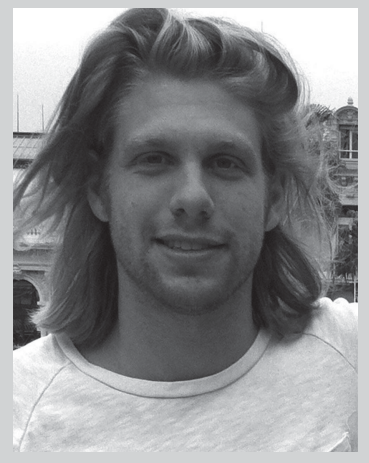

Tomas Leijtens is a Ph.D. candidate at the University of Oxford, under supervision of Prof. Henry J. Snaith. He holds an "Early Stage Researcher" Marie Curie fellowship at the Center for Nano Science and Technology in Milan, Italy. His research is primarily focused on understanding charge-transport mechanisms in solution-processed semiconductors and the influence thereof on both the performance and long-term stability of hybrid photovoltaic devices.

Prof. Henry Snaith has been at

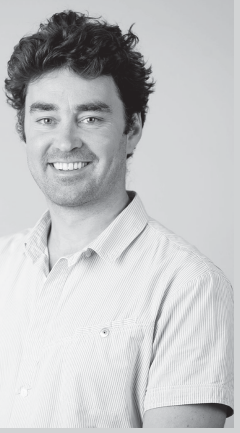
Oxford University since 2007. He undertook his Ph.D. at the University of Cambridge, and post-doc at the EPFL, Switzerland. His research achievements include the first demonstration of "gyroid" structured titania for dye-sensitized solar cells, the first demonstration of mesoporous single crystals of $\mathrm{TiO}_{2}$, and the recent discovery of high-efficiency organometal trihalide perovskite-based solar cells. In 2010 he founded Oxford Photovoltaics

Ltd., which is rapidly commercializing perovskite solar cells. 

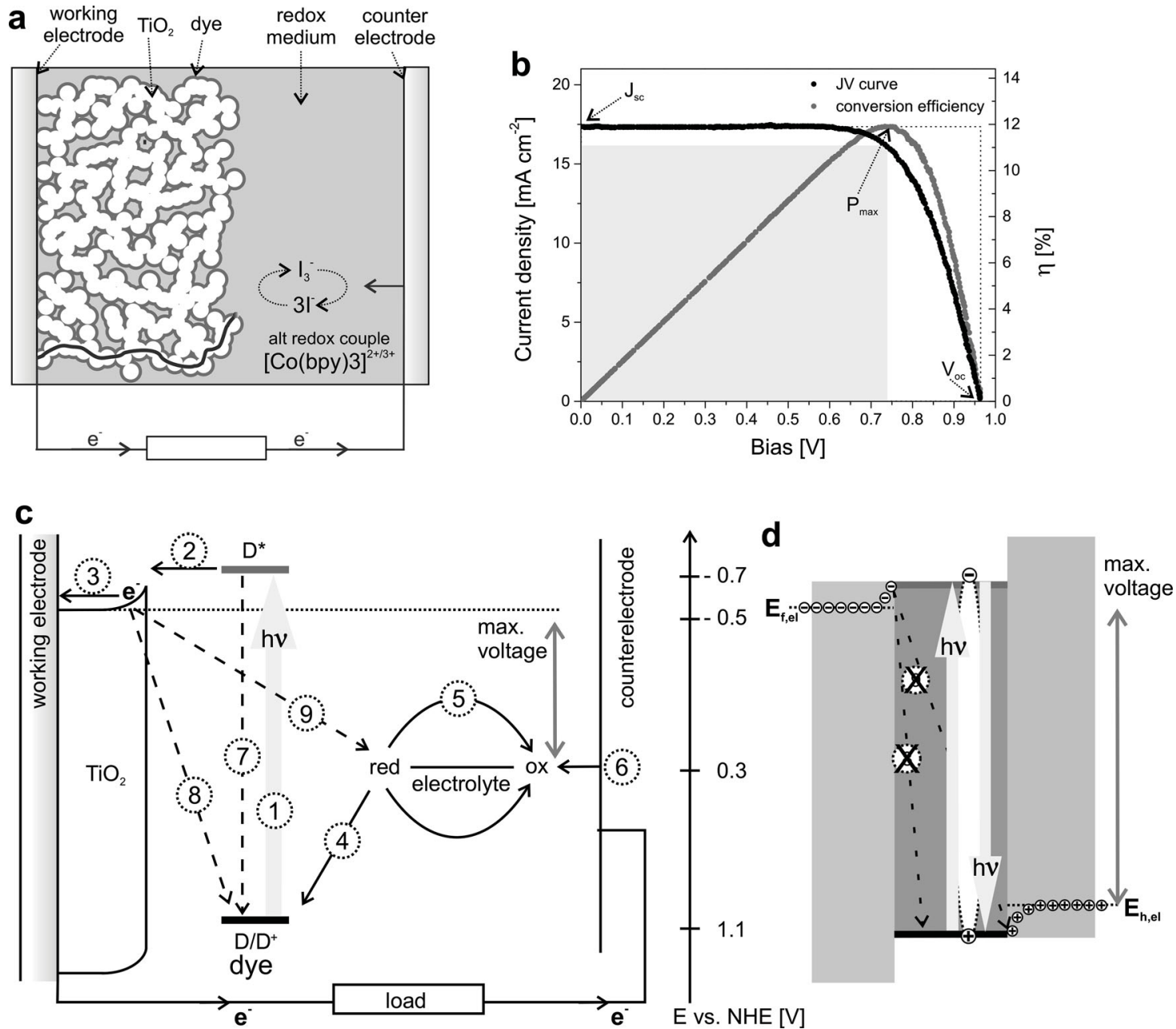

Figure 1. Key device characteristics of dye-sensitized solar cells. a) Schematic of a conventional device architecture. Nanometer-sized TiO $\mathrm{N}_{2}$ particles form an electron-conducting random network with high surface area. A monolayer of light-absorbing dye molecules is chemisorbed onto the $\mathrm{TiO}_{2}$ and surrounded by an electrolyte. Upon photoexcitation of the dye, electrons are injected into the $\mathrm{TiO}_{2}$, while the oxidized dye is regenerated by the electron-donating redox medium, which is subsequently reduced at the counter electrode. b) Current-voltage $(U-V)$ characteristics of a conventional DSSC under illumination. c) Energy-level diagram of a conventional liquid-electrolyte DSSC. The energy levels $E$ are given with respect to a normal hydrogen electrode (NHE). d) Schematic of an idealized molecular heterojunction device, where recombination only occurs via radiative pathways. a,c) Adapted with permission. ${ }^{[261]}$ Copyright 2013, Springer Int. Publishing.

and the competing charge-recombination processes:

7. Excited-state decay of the dye ${ }^{[34]}$

8. Regeneration of the oxidized dye by back transfer of $\mathrm{TiO}_{2}$ injected electrons ${ }^{[42]}$

9. Recombination of injected electrons with acceptor species in the redox medium ${ }^{[43,44]}$

DSSCs are a promising photovoltaic concept for a number of reasons. Unlike conventional p-n junction solar cells, where electron-hole pairs are generated in the bulk and then need to diffuse to the p-n interface in order to be extracted, charge generation in DSSCs only takes place at the materials interface. As a consequence, the demand on material purity is much lower, which implies that processing under vacuum, ultrahigh temperature or cleanroom classification is generally not necessary. ${ }^{[45]}$

Recent advances in the synthesis of organic dyes have eliminated the need for the rare ruthenium-based sensitizers, which means that all device components are now abundant and promise significantly lower processing costs than existing technologies. ${ }^{[33,46]}$ The variety of colours and transparencies distinguishes DSSCs from other photovoltaic concepts and makes them ideally suited for integrated architecture and building design. ${ }^{[47,48]}$

Nevertheless, and despite enormous research efforts, highperformance DSSCs with $\eta_{\max }=12.3 \%$ lag behind other technologies and fall short of their theoretically attainable efficiency. ${ }^{[15,33]}$ When consolidating efficiency parameters and experimental results presented in Figure 1, several key points for further efficiency enhancement are evident: loss in fill factor, loss in potential, and loss in absorption/photocurrent.

\subsection{Loss in Fill Factor}

Although most efficient DSSCs exhibit near unity charge collection efficiencies at short-circuit conditions, devices operate less 
efficiently when approaching open circuit. Part of this problem may be easily explained by series resistance arising from the solar-components ${ }^{[39,40,49]}$ and recombination losses. ${ }^{[50-53]}$ Additional losses arise from dark current processes at the interface between the metal oxide and the hole-transporting material, which are present even in devices exhibiting close to unity charge collection efficiencies at maximum power conditions. ${ }^{[54,55]}$ We will explore recent developments in photoanode design to address these issues in Section 3.

\subsection{Loss in Potential}

Intrinsic losses in DSSCs arise from the overpotential required to drive the multitude of charge-carrier transfer pro-cesses, as illustrated in Figure 1c. In a conventional iodine-based redox couple, the total overpotential may be as high as $600-700 \mathrm{mV}$. In order to minimize this loss, several solutions have been put forward employing either alternative redox couples ${ }^{[3,56-69]}$ or solid-state hole-transporting materials $(\mathrm{HTMs}) \cdot{ }^{[70-80]}$ Since comprehensive reviews about alternative redox electrolytes can be found elsewhere, ${ }^{[66-69]}$ we will focus on challenges and opportunities that arise from the use of solid-state HTMs in Section 4.

\subsection{Loss in Absorption/Photocurrent}

The IPCE can reach values of up to $80-90 \%$ in high efficiency devices, but only in a limited spectral range. ${ }^{[81]}$ The development of dyes which have higher extinction coefficients and a more panchromatic absorption is therefore essential, but challenged by a potential cost to the open-circuit voltage. ${ }^{[82]}$ Additionally, light capture may be enhanced significantly by the addition of scattering layers, ${ }^{[32,81]}$ one-dimensional or three-dimensional photonic crystals, ${ }^{[83-85]}$ or plasmonic elements. ${ }^{[86-88]}$ It remains a handicap that DSSCs only achieve good performance when a monolayer of sensitizer is deposited. ${ }^{[89,90]}$ As a consequence, the mesoporous photoanode needs to be relatively thick, which leads to charge transport and recombination related losses. Increasing device thickness also leads to enhanced losses due to parasitic absorption from the doped HTMs in solid state DSSCs, as discussed in Section 4. In Section 5 we explore how alternative inorganic sensitizers can somewhat circumvent these problems.

\section{Towards an Ideal Photoanode Architecture}

\subsection{Electrode Morphology}

Several requirements concerning the morphology of the electron-conducting photoanode are apparent when studying the operating principles of DSSCs. Since photons are only absorbed at the n-dye-p interface, the photoanode needs to exhibit an extremely large surface to multiply the available area for dye anchoring. Even for modern dyes with high extinction coefficients, the photosensitive interfacial area has to be a hundred-to a thousand-fold greater than that of a flat film. Upon excitation and electron injection, the oxidized dye requires prompt reduction by a surrounding regenerating medium. The pores of the electron-conducting network therefore need to be large enough to allow ion diffusion of a solution-based electrolyte or pore infiltration by a solid-state hole conductor. Furthermore, the porous network has to offer direct percolation paths for the extraction of charges. Thus, an idealized photoanode morphology should be mesoporous (i.e., exhibit porosity on the $10 \mathrm{~nm}$ length scale), bicontinuous and offer sufficiently high charge-carrier transport.

The efficiency leap in the seminal work of O'Regan and Grätzel in 1991 was mainly due to a novel photoanode structure which sufficiently fulfilled these requirements - a mesoporous network generated by the random sintering of $20 \mathrm{~nm}$-sized $\mathrm{TiO}_{2}$ particles. Although random in pore size and morphological order, this electrode structure is still the gold standard in today's devices and a fundamental component in all recordbreaking DSSCs. ${ }^{[32,33]}$ However, several drawbacks arise from the random sintering of nanoparticles to form a mesoporous network, namely poor charge transport, ${ }^{[91]}$ a lack of control over the pore-size distribution ${ }^{[92]}$ and network geometry, ${ }^{[93]}$ as well as a high density of sub-bandgap states, which introduce broad energetic disorder. ${ }^{[94]}$ The electron mobility typically decreases by several orders of magnitude from a value of $\mu \approx 10 \mathrm{~cm}^{2} \mathrm{~V}^{-1} \mathrm{~s}^{-1}$ for single-crystal anatase ${ }^{[95]}$ to around $\mu \approx 10^{-1}-10^{-5} \mathrm{~cm}^{2} \mathrm{~V}^{-1} \mathrm{~s}^{-1}$ in nanoparticle films. ${ }^{[91,96-98]}$

Alternative materials for DSSC photoanodes are $\mathrm{ZnO}^{[99-101]}$ or $\mathrm{SnO}_{2} \cdot{ }^{[102,103]}$ Core-shell strategies were proposed to combine high charge-carrier mobilities with low recombination rates. ${ }^{[102-105]}$ However, while the bulk mobility of $\mathrm{SnO}_{2}$ is witharound $200 \mathrm{~cm}^{2} \mathrm{~V}^{-1} \mathrm{~s}^{-1}$ significantly higher than that of $\mathrm{TiO}_{2}$, electron-transport dynamics have proven to be rather similar in these two materials for comparable morphologies and crystallinities. ${ }^{[97,106-108]}$

A further drawback of the standard nanoparticle network for new-generation DSSCs is the lack of control over the pore-size distribution. ${ }^{[92]}$ Cobalt complexes are bulky and therefore need well-defined percolation paths with sufficiently large pores to avoid mass transport limitations to the counter electrode. ${ }^{[33,109]}$ For solid-state DSSCs, a heterogeneous pore-size distribution may reduce pore filling when infiltrating the viscous materials. ${ }^{[110,111]}$

Alternative electrode architectures for DSSCs have been intensely studied in recent years. The motivation for this has been mostly the control of the electrode morphology, the improvement of light management, the enhancement of charge-carrier transport or the facilitation of solid-state HTM infiltration. We refer to reviews on electrode architectures ${ }^{[112,113]}$ and photonic aspects for a full overview. ${ }^{[85,114]}$

An active area of research is focused on the development of $1 \mathrm{D}$ structures, such as $\mathrm{TiO}_{2}$ nanorods or nanotubes. In principle these structures should exhibit greatly enhanced chargecarrier transport properties as the percolation path is 1D and therefore rather direct (Figure $2 \mathrm{a}-\mathrm{c}$ ). ${ }^{[115]}$ Advances in the electrochemical anodization of titanium have led to the fabrication of $\mathrm{TiO}_{2}$ nanotubes up to ca. $20 \mu \mathrm{m}$ long. ${ }^{[116]}$ Unfortunately, these 1D arrays suffer from a greatly reduced surface area per unit volume due to their collapse and lack of nanoporosity associated with the roughness of nanometre-sized crystals. Efforts were therefore drawn towards the fabrication of hierarchical 

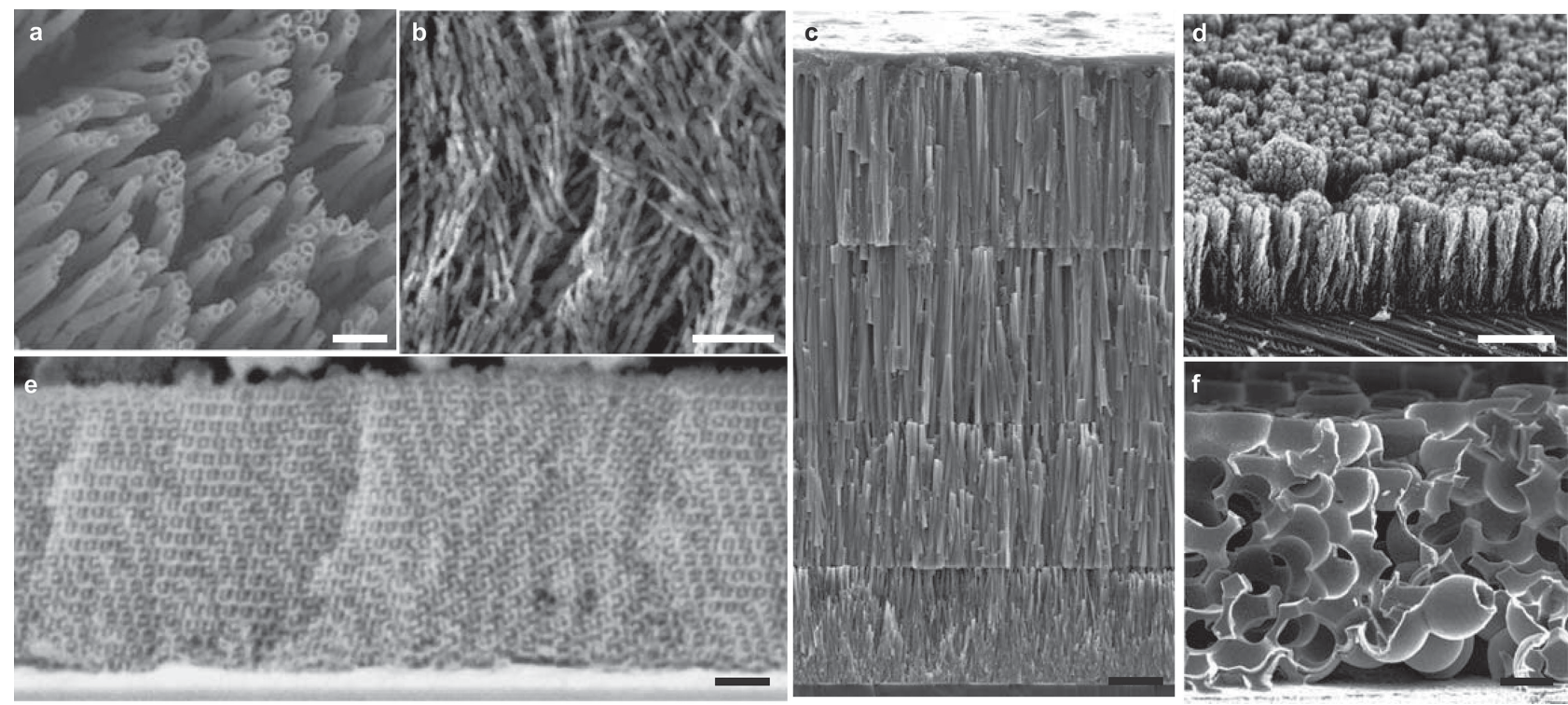

Figure 2. Novel electrode architectures for DSSCs. a) Top-view of ca. $20 \mu \mathrm{m}$ long $\mathrm{TiO}_{2}$ nanotubes, grown by electrochemical anodisation of titanium. b) Top-view of a 3D fibrous network of crystalline $\mathrm{TiO}_{2}$ nanowires synthesised by hydrothermal growth. c) Multilayer array of $\mathrm{TiO}_{2}$-coated $\mathrm{ZnO}$ nanowires. d) Cross-sectional view of an array of hierarchical, tree-like $\mathrm{TiO}_{2}$ nanostructures generated by pulsed lased deposition. e) Cross-sectional view of $\mathrm{TiO}_{2}$ resembling the bicontinuous gyroid morphology generated by electrochemical deposition of $\mathrm{TiO}_{2}$ into a sacrificial block-copolymer template. f) 3D photoanode by colloidal assembly and multilayer atomic layer deposition. a) Adapted with permission. ${ }^{[116]}$ Copyright 2009, Macmillan Publishers Ltd. b) Adapted with permission. ${ }^{115]}$ Copyright 2010, American Chemical Society. c) Adapted with permission. ${ }^{[134]}$ Copyright 2012, American Chemical Society. d) Adapted with permission. ${ }^{[17]}$ Copyright 2010, American Chemical Society. e) Adapted with permission. ${ }^{[125]}$ Copyright 2009, American Chemical Society. f) Adapted with permission. ${ }^{[133]}$ Copyright 2011, American Chemical Society.

structures which are typically tree-like. Ideally these consist of a highly conductive one-dimensional backbone that branches out into a network of feeding pathways, thus enhancing charge transport and maintaining a high enough surface area. Hierarchical assemblies have been realized by pulsed laser ablation $^{[117-119]}$ (Figure 2d) or hydrothermal growth, which was initially shown for $\mathrm{ZnO}^{[120]}$ and more recently in various $\mathrm{TiO}_{2}$ based architectures. ${ }^{[121,122]}$

Molecular self-assembly may offer the highest degree of 3D structure control on the $10 \mathrm{~nm}$ length scale. One example is block copolymers (BCPs), which can self-assemble into highly ordered, bicontinuous film morphologies on the $10 \mathrm{~nm}$ length scale and allow morphology replication by inorganic materials. Accessible film morphologies include assemblies such as interdigitated cylindrical arrays or the bicontinuous gyroid, which exhibits a 3D network of monodisperse pores, where all channels and struts are fully interconnected. ${ }^{[123,124]} \mathrm{A}$ freestanding $\mathrm{TiO}_{2}$ gyroid network is shown in Figure 2e, which was fabricated by electrochemical deposition of $\mathrm{TiO}_{2}$ into one selectively degraded phase of a block-copolymer film. ${ }^{[125]}$ Another example is the co-assembly of inorganic materials by BCPs. ${ }^{[126]}$ Here, the $\mathrm{TiO}_{2}$ precursor material is directly mixed with the $\mathrm{BCP}$ solution and during solvent evaporation, the structure of the inorganic components is directed by BCP self-assembly due to selective complexation with one of the copolymer blocks. Control over pore size, porosity, and charge-transport properties has led to a number of promising studies, particularly in solid-state DSSCs. ${ }^{[127,128]}$ A variety of other soft-matter systems have also been used for structure control in $\mathrm{TiO}_{2}$ photoanodes, including the assembly of colloidal spheres ${ }^{[129,130]}$ or the M13 virus. ${ }^{[131]}$ An intriguing concept is the structuring of the underlying transparent conducting oxide electrode which allows radial charge-carrier collection and therefore a greatly reduced electron percolation path. ${ }^{[132,133]}$

Despite many promising studies that have reported relative improvements compared to a reference, maximum efficiency devices still incorporate the standard nanoparticle-based electrode. Many device architectures indeed outperform the nanoparticle-based electrode on single aspects, such as charge-transport properties, pore accessibility or light scattering. ${ }^{1115,124,131,133]}$ Nevertheless, combining a high-enough surface area with improved charge-carrier transport and efficient light harvesting in a high-efficiency device remains a challenge.

\subsection{Overcoming Electronic Disorder}

Here, we draw attention to an aspect of electrode design which is often overlooked, the control of electronic disorder. While researchers have developed tools to generate near-optimum morphological order, controlling the actual electron pathways does not necessarily follow from the mesoscale arrangement of $\mathrm{TiO}_{2}$. Even so-called 1D features such as $\mathrm{TiO}_{2}$ tubes and wires are often polycrystalline, with pathways that are much larger than the electron scattering length. ${ }^{[135-137]}$

Historically, the poor electronic properties of a random nanoparticle network were not a major limiting factor due to the slow recombination kinetics of the iodine-based redox couple. ${ }^{[138]}$ Nevertheless, one of the main recent trends involve the reduction of the loss in potential and the improvement of device efficiency by moving from a two-electron to a one-electron regeneration process. This strategy has resulted in new record 

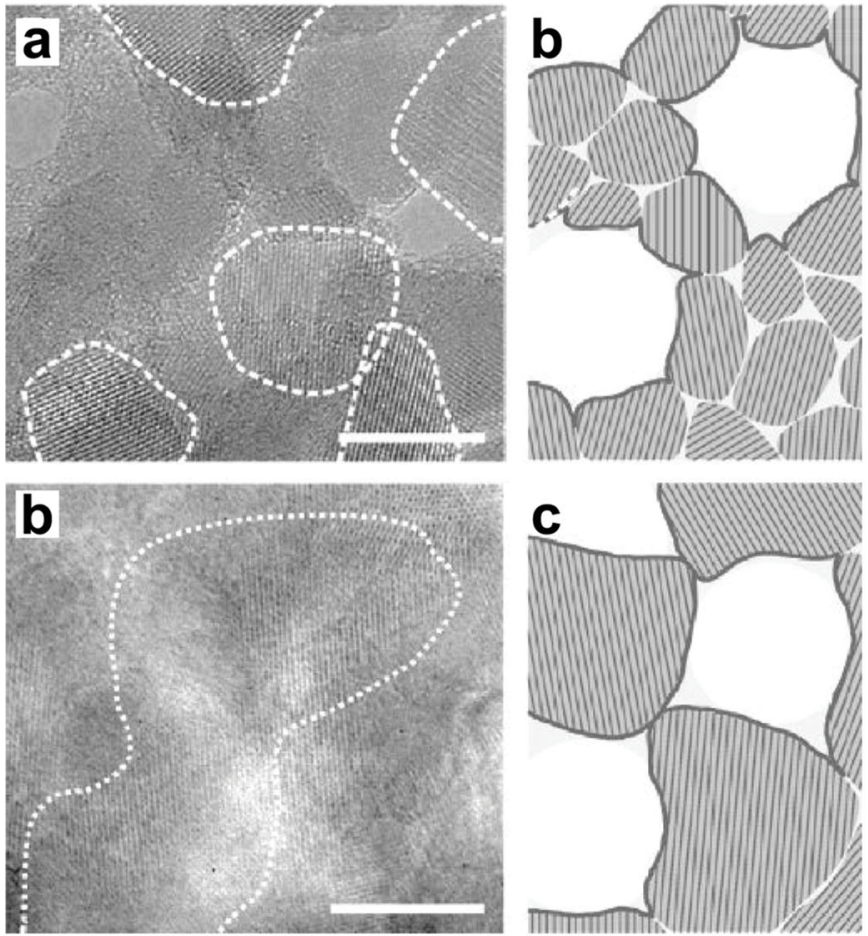

Temperature $\left({ }^{\circ} \mathrm{C}\right)$
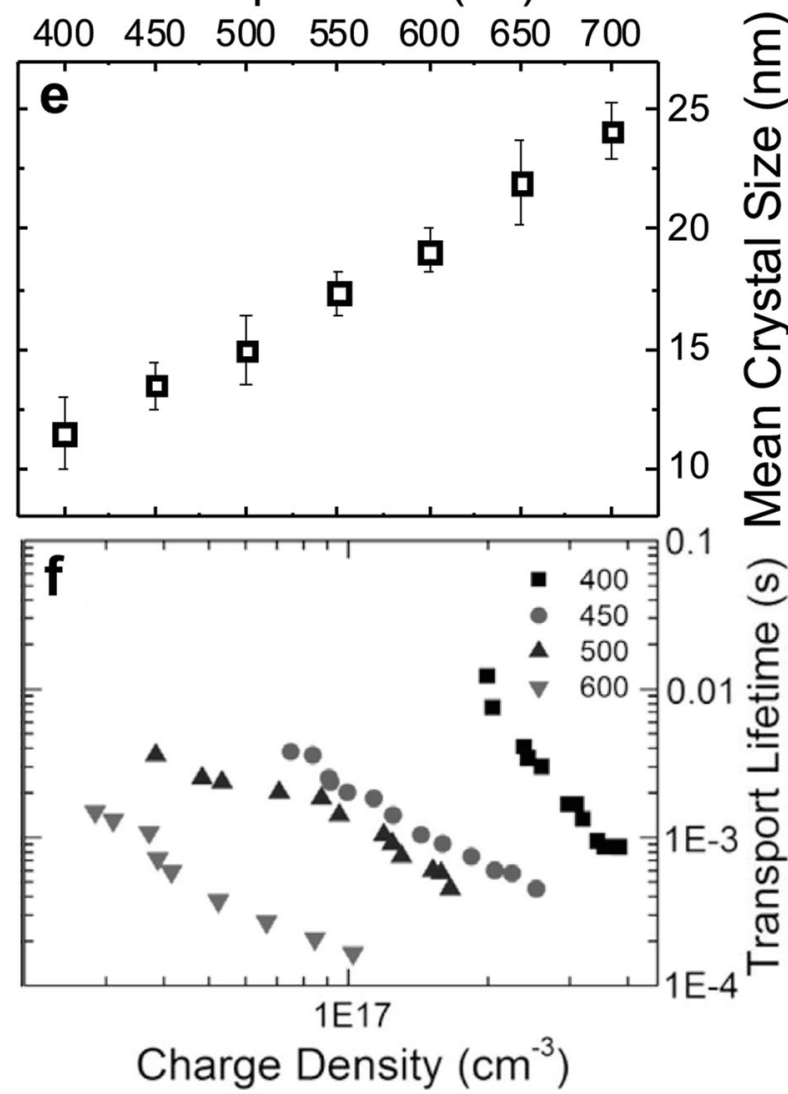

Figure 3. Nanocrystal assembly within a mesoporous $\mathrm{TiO}_{2}$ network. High-resolution transmission electron microscopy images and corresponding schematic of BCP-directed assemblies crystallized at: a,b) $450{ }^{\circ} \mathrm{C}$ and c,d) $650{ }^{\circ} \mathrm{C}$, respectively. The scale bars represent 10 nm. The white dotted lines visualize the individual crystallites. e) Crystallite size as a function of calcination temperature. $\mathrm{f}$ ) Photocurrent decay vs. charge density for photoanodes that were crystallized at a range of temperatures. a-d) Adapted with permission. ${ }^{[45]}$ Copyright 2011 , Royal Society of Chemistry. e,f) Adapted with permission. ${ }^{[146]}$ Copyright 2013, American Chemical Society.

efficiencies in liquid-electrolyte ${ }^{[33]}$ and solid-state DSSCs. ${ }^{[19]}$ However, due to faster recombination kinetics in one-electron redox systems, the poor electron-transport properties of nanoparticle-based films deteriorate the photocurrent, fill factor, and photovoltage through low charge-collection efficiencies, fast interfacial recombination, and high internal resistance. ${ }^{[94,109]}$ In fact, charge transport in DSSCs appears to be "electron-limited" at short circuit, meaning that the transport of electrons through the mesoporous $\mathrm{TiO}_{2}$ is slower than the transport of holes through the hole-transporting medium. ${ }^{[40,98,139,140]}$

In comparison to a single-crystal model system where only optical phonon scattering and lattice defects limit the mean free path of propagating electrons, ${ }^{[141]}$ a number of factors slow down electron diffusion in polycrystalline networks. These include charge traps located at the grain boundaries between the crystals, their surfaces, and in the bulk. These lead to the formation of an exponentially decreasing tail of sub-bandgap states below the conduction band edge. ${ }^{[52,142]}$ It is widely agreed that electron transport in such mesoporous networks is consistent with a multiple trapping model, where generated electrons mostly populate localized states below the conduction band and only diffuse towards the electrode in iterative cycles of thermal detrapping and trapping. ${ }^{[52,53,142-144]}$
The crystal size was recently shown to have a profound effect on charge-transport properties and performance of solid-state devices. ${ }^{[137,145,146]}$ In order to isolate the role of the mean crystallite size on the electrode performance, BCP generated photoanodes with a similar surface areas and morphologies but widely varying crystal sizes were examined.[145,146] The main results are reprinted in Figure 3, where the chargetransport lifetime is shown to be heavily influenced by the crystal size of the mesoporous titania, although no significant change to the density of trap states exists. In a related study on single-crystal nanowires, it was shown that transport can be improved in such a way that the system can become hole limited even at short-circuit conditions, emphasizing the limitations due to the polycrystalline nature of the mesoporous oxide. ${ }^{[137]}$ Notably, a decoupling of transport and recombination dynamics was observed. Charge-transport dynamics were limited by the HTM, while recombination dynamics remained unchanged when single-crystalline nanowires were used. ${ }^{[137,146]}$ This result is particularly important since for transport-limited recombination: any improvement in charge diffusion would result in a corresponding increase in recombination. ${ }^{[147]}$ The fact that this is not the case in sSDSSCs implies that there is much scope to improve device 
performance by increasing the charge transport in the photoanode.

The ideal photoanode therefore is a singlecrystalline structure with a tunable and accessible network of pores and a high surface area. The highest electron-transport rates are expected in systems that consist of single-crystalline wires ${ }^{[148,149]}$ or quasi-single crystallites that are formed through the oriented attachment of crystalline fragments. ${ }^{[115,150,151]}$ Singlecrystalline nanowires can be grown hydrothermally off titanium foils in the preferred anatase crystal structure, ${ }^{[152]}$ with improved dye-loading by optional nanorod branches. ${ }^{[153]}$

The extension of this approach towards full 3D control of crystal growth in controlled geometries has recently been demonstrated with the synthesis of mesoporous single crystals of anatase $\mathrm{TiO}_{2}$ with crystal sizes ranging from a few hundred $\mathrm{nm}$ to $3 \mu \mathrm{m}$ and independently tunable pore sizes varying from 20 to $250 \mathrm{~nm}$. ${ }^{[1]}$ The combination of mesoporosity and single crystallinity was enabled by seeded nucleation and growth inside a mesoporous template. ${ }^{[154]}$ Thin films of mesoporous single-crystal assemblies exhibit "nanowire-like" transport while maintaining a sufficiently high surface area for dye adsorption, shown in Figure 4. An important technological benefit of this approach is that mesoporous single-crystal assemblies do not require thermal sintering to ensure good electrical connectivity in the photoanode. This was recently demonstrated by the complete fabrication of a solid-state ssDSSC device below $150{ }^{\circ} \mathrm{C}$ with a power conversion efficiency of over 3\%.[17] Apart from promising efficiency improvements, low-temperature processing greatly simplifies manufacture, enables a broad choice of substrates including plastic foils for low cost flexible solar cells, ${ }^{[155]}$ and will enable multiple junction fabrication.

\section{Hole-Transporting Materials}

A fundamental constraint imposed by the use of the iodine-based redox shuttles is the overpotential that is required to drive the redox reaction (i.e., $3 \mathrm{I}^{-} / \mathrm{I}_{3}^{-}$) and likewise for the cobalt system. ${ }^{[15]}$ Even in the light of proposed strategies to minimize overpotential losses associated with the 2-step hole-regeneration process, ${ }^{[49,138]}$ these solar cells unavoidably suffer a loss in photovoltage, significantly limiting the maximally attainable performance well below the Schockley-Queisser limit. ${ }^{[15]}$ In an effort to overcome these limitations, polypyrrole-based solid-state hole-transporting materials (HTMs) were introduced by Yanigida and co-workers. ${ }^{[70]}$ Shortly after, Bach and Grätzel developed the now common form of ssDSSCs using a small-molecule-based HTM
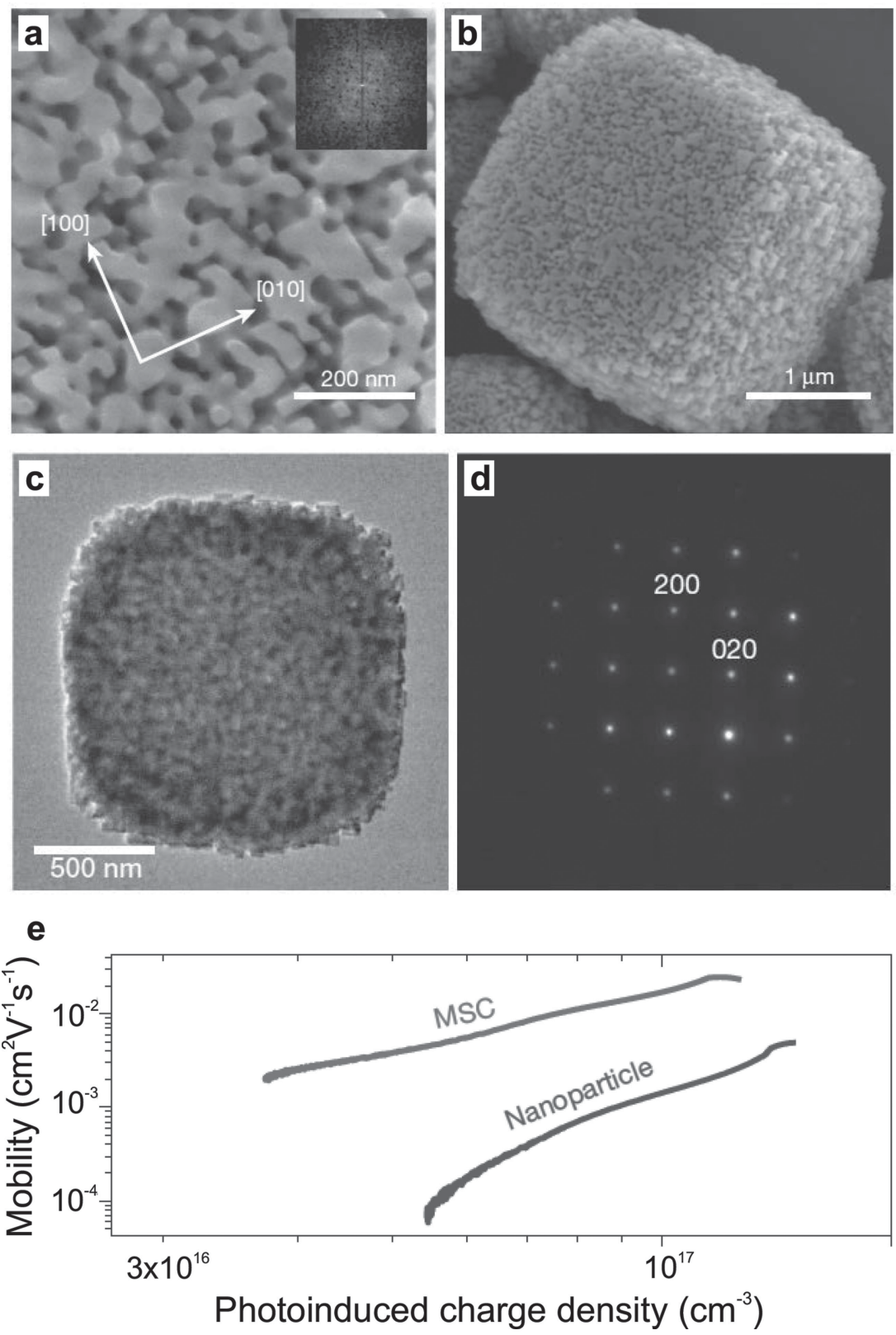

Figure 4. Mesoporous single crystals of anatase $\mathrm{TiO}_{2}$ : a) Single-crystal replication of the mesoporous template extending to micrometer-sized domains (b). c) Transmission electron micrograph and d) corresponding Laue pattern of a single-crystalline building block. e) Mobility dependence on photoinduced charge density for MSC and nanoparticle films. a-e) Adapted with permission. ${ }^{[17]}$ Copyright 2013, Macmillan Publishers Ltd.

that can be infiltrated into the porous $\mathrm{TiO}_{2}$ anode. ${ }^{[71]}$ This HTM is a triphenylamine-based molecule termed spiro-OMeTAD (2,2' $, 7,71$-tetrakis(N,N'-di-p-methoxyphenylamine)-9,9' -spirobifluorene), and while several alternatives have been proposed, ${ }^{[72-80]}$ spiro-OMeTAD still remains the most widely used and best performing solid-state hole-transporting material.

Table 1 provides a list of the highest performance HTMs, both small molecule and polymer-based, along with relevant properties that are addressed below. For more-in-depth discussion of the various HTMs employed in SSDSSCs, the reader is 
Table 1. Summary of the relevant properties and structure of some of the most highly performing solid-state hole transporters.
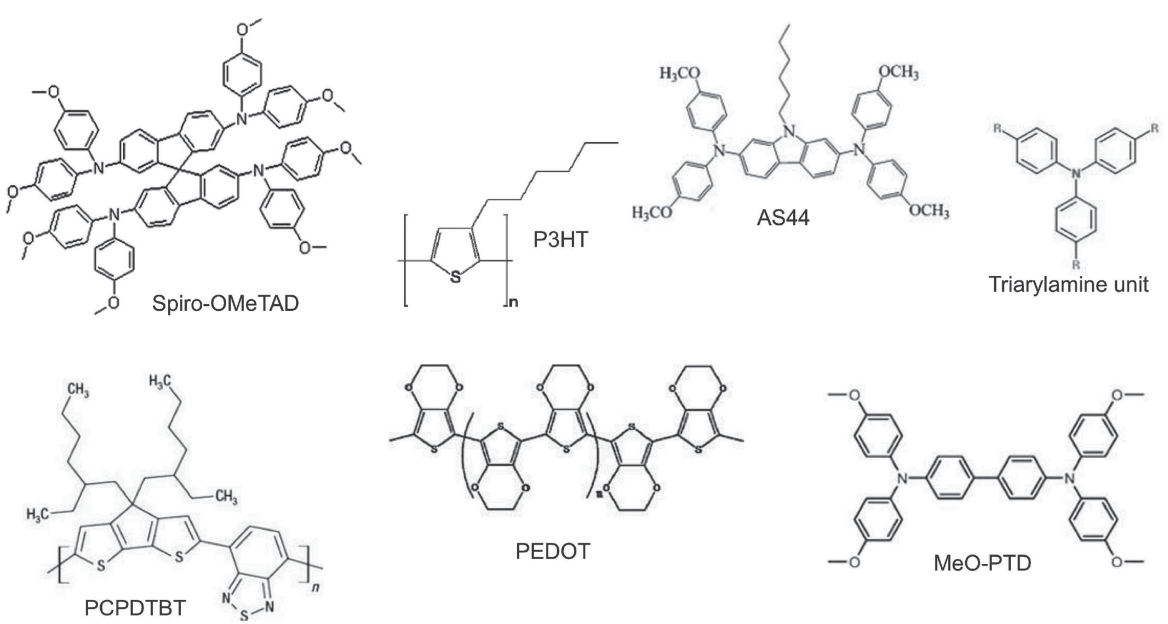

PEDOT

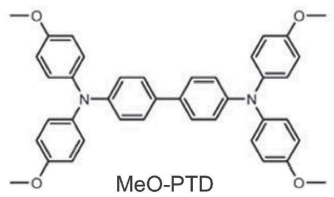

\begin{tabular}{lccccc}
\hline & Molecular Mass & $\begin{array}{c}\text { HOMO Level } \\
{[\mathrm{eV}]}\end{array}$ & $\begin{array}{c}\text { Mobility } \\
{\left[\mathrm{cm}^{2} \mathrm{~s}^{-1}\right]}\end{array}$ & $\begin{array}{c}\text { Record PCE } \\
{[\%]}\end{array}$ & Notes \\
\hline Spiro-OMeTAD & Small molecule & -4.9 & $1-50 \times 10^{-5}$ & $7.2^{[19]}$ & Absorbs when doped \\
P3HT & Polymer & -4.8 & $1 \times 10^{-3}$ & $3.2^{[159]}$ & Competes for light absorption \\
PCPDTBT & Polymer & -5.3 & $10^{-4}-10^{-2}$ & $1.4^{[78]}$ & Competes for light absorption \\
PEDOT & Polymer & -5.2 & $>0.1$ & $6.8^{[160]}$ & Highly doped and conductive \\
AS44 & Small molecule & -4.8 & $10^{-5}$ & $2.9^{[75]}$ & Highly soluble, melt processable \\
Triarylamines & Var. & $-5.3-4.0$ & $1-10 \times 10^{-5}$ & $2.0^{[72]}$ & Tunable, melt processable \\
MeO-TPD & Small molecule & -5.1 & $1 \times 10^{-3}$ & $4.9^{[80]}$ & Requires 30 min of light soaking \\
\hline
\end{tabular}

referred to several comprehensive reviews. ${ }^{[76,156-158]}$ The use of these HTMs has increased the photovoltages to over $900 \mathrm{mV}$ in traditional dye-sensitized solar cells, along with respectable power conversion efficiencies of up to $7.2 \%$. ${ }^{[19]}$

This power conversion efficiency, while high, is a long way from the theoretical performance of $20 \%{ }^{[15]}$ The ssDSSC is largely limited by the fact that the optimized device thickness is only about $2 \mu \mathrm{m}$, which is significantly thinner than the optical depth of the composite. The origin of this limitation is still much debated, and will be addressed below. Nevertheless, this imposes limits to the choice of dyes that can be used to efficiently harvest light since they must exhibit very high absorption coefficients. ${ }^{[15,19,94,161]}$ We have explored in the previous section the effects of the mesoporous photoanode in the performance of the device, and have shown that, by utilizing systems consisting of extended crystallites, electron-transport limitations can be effectively eliminated from the devices. ${ }^{[17,137]}$ We therefore focus on the effects, challenges and limitations arising from the use of HTMs in this section.

\subsection{Pore Filling}

Insufficient infiltration of the mesoporous $\mathrm{TiO}_{2}$ with the solidstate HTM has widely been assumed to cause the thickness limitations in ssDSSCs, resulting in poor diffusion lengths or light-harvesting capabilities of the dye-sensitizers. ${ }^{72,75,110,162,163]}$ The pore-filling mechanism in SsDSSCs has been the intense focus of a number of research groups. Several strategies to quantitatively evaluate of pore-filling were recently developed, including photoinduced absorption spectroscopy, ${ }^{[164]}$ analysis by electron microscopy, ${ }^{[162]}$ a combination of X-ray photoelectron and UV-Vis absorption spectroscopy ${ }^{[111,163]}$ and white light interferometry. ${ }^{[165]}$ For a standard nanoparticle-based electrode, a pore filling fraction of no more than $60 \%$ has been found to enable optimum performance. ${ }^{[111,163,165]}$ This is now readily achieved for mesoporous films with thicknesses of up to $5 \mu \mathrm{m}$, suggesting that other factors limit the device thickness, including poor charge transport in the metal oxide and other aspects of the HTM that are discussed below.

Infiltration is more challenging for high-molecular-weight polymeric HTMs, which exhibit pore filling fractions as low as $8 \%$ when following standard deposition protocols. ${ }^{[74]}$ In order to improve this pore filling fraction, in situ polymerization of the monomers has been employed with a satisfactory outcome. ${ }^{[156,166,167]}$ Alternatively, pre-coating of the mesoporous metal oxide with bis(trifluoromethane)sulfonimide lithium salt (LiTFSI) and tert-butylpyridine ( $t \mathrm{BP})$ has been found to facilitate sufficient infiltration. ${ }^{[74]}$ Although the pore-filling fraction for polymers is much lower than the small molecules, they nevertheless form a good charge percolation network, even at low pore-filling fractions. ${ }^{[74]}$

\subsection{The Importance of Hole Mobility and p-Doping in HTMs}

Since the introduction of the first SsDSSCs based on spiroOMeTAD, there has been some debate about the importance 
of doping and charge transport in HTMs. Some have claimed that in optimized solar cells, performance is limited by the low $\left(10^{-5}-10^{-3}\right)$ hole mobility in the HTM. ${ }^{[71,168]}$ It was proposed that such a low mobility limits the charge-diffusion length and hence photocurrent in solar cells. ${ }^{[67,140,169]}$ As a result, a great deal of research effort has focused on the development of high mobility HTMs $\left(>10^{-3} \mathrm{~cm}^{2} \quad \mathrm{~V}^{-1} \mathrm{~s}^{-1}\right) \cdot{ }^{[72,80,159,167,170]}$ Some notable examples include in situ polymerized poly[3,4ethylenedioxythiophene] (PEDOT), poly[3-hexylthiophene] (P3HT), or poly[2,6-(4,4-bis-(2-ethylhexyl)-4H-cyclopenta[2,1$b ; 3,4-b^{\prime}$ ]dithiophene)-alt-4,7(2,1,3-benzothiadiazole)] PCPDTBT. ${ }^{[7,78,160,167]}$ While power conversion efficiencies over $6 \%$ were achieved, the performance of devices incorporating these HTMs was in part limited by light absorption in the polymer and low electron transfer into $\mathrm{TiO}_{2}{ }^{[78,112,159,171-173]}$ even after $\mathrm{TiO}_{2}$ surface modification, resulting in an overall reduction in photocurrent. ${ }^{[78,174,175]}$ Special care must be taken when measuring the performance of ssDSSCs incorporating these materials, since if the cells are not masked properly, the actual area from which charges are collected can be up to twice as large as the area covered by the metal cathode, resulting in a tremendous overestimation of device performance. ${ }^{[176]}$

Despite research efforts towards high-mobility HTMs, the "low-mobility" spiro-OMeTAD has remained the gold standard in ssDSSCs. ${ }^{[19]}$ Indeed, by varying the molecular structure and associated hole mobilities of a range of HTMs, Kroeze et al. demonstrated that the hole mobility of the HTM has little effect on the short-circuit photocurrent of the solar cells when the widely employed $t$ bp and Li-TFSI additives were used. ${ }^{[72]}$ Snaith et al. compared the conductivities of spiro-OMeTAD and $\mathrm{TiO}_{2}$ in dye-sensitized solar cells in situ, which suggests that the hole conduction in an operational dye-sensitized solar cell is significantly faster than electron conduction through the $\mathrm{TiO}_{2} \cdot{ }^{[139]}$ The conclusion of these studies, and of others successfully employing relatively low-mobility HTMs, ${ }^{[75,80]}$ was that the hole mobility of spiro-OMeTAD does not limit the chargediffusion length and hence device performance.

The concept that either the hole or electron transport limits device performance of dye-sensitized solar cells may however be overly simplistic. Fabregat-Santiago et al. have found that while electron transport limits charge diffusion at low potentials, hole transport limits charge transport in ssDSSCs at the high charge densities typically found at forward bias. ${ }^{[169]}$ This result was recently confirmed by the use of transient mobility spectroscopy (TMS), determining the charge-density dependence of mobility and conductivity for both $\mathrm{TiO}_{2}$ and hole transporters (see Figure 5). ${ }^{[98]}$ The cross-over region where hole conductivity limits the solar cell only occurs when spiro-OMeTAD is doped with Li-TFSI.

The presence of Li cations has several effects on ss-DSSC performance. On the one hand, they greatly increase the conductivity of spiro-OMeTAD and polymeric HTMs such as P3HT and PCPDTBT (Figure 5 and Figure 6) via a catalyzed oxidative process. ${ }^{[7,98,177-181]}$ On the other hand, they influence the surface states and potential of the $\mathrm{TiO}_{2}$, manipulate dye injection, electron-transport and recombination rates, and affect dye-absorption spectra. ${ }^{[177,179,182-184]}$ These parameters are also influenced by the presence of $t \mathrm{BP}$ and the relative amount of the additives seems to determine the overall balance of these
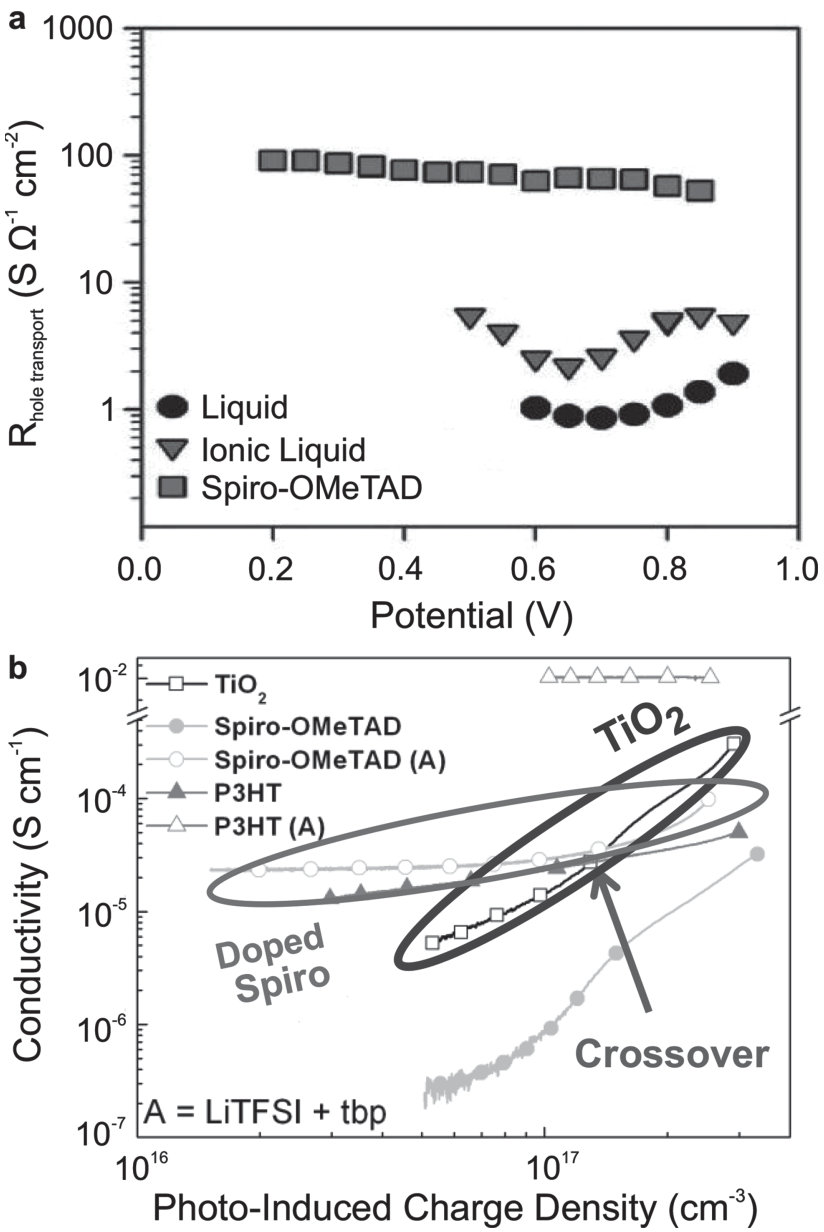

Figure 5. Description of hole transport in the solid-stateDSSCs. a) The hole-transport resistance (extracted from impedance spectroscopy) of liquid-, ionic-liquid, and spiro-OMeTAD-based HTMs in ssDSSCs are plotted as a function of potential. b) Conductivity of $\mathrm{TiO}_{2}$ (black open squares), doped (light-grey open circles) and undoped (grey solid circles) spiro-OMeTAD, doped (light-grey open triangles) and undoped (grey closed triangles) $\mathrm{P} 3 \mathrm{HT}$ as a function of photoinduced charge density. The data in (b) is derived from TMS measurements of solar-cell devices, demonstrating the cross-over point of electron to hole-limited charge conduction. a) Reproduced with permission. ${ }^{[169]}$ Copyright 2009, American Chemical Society. b) Adapted with permission. ${ }^{[98]}$ Copyright 2013, Wiley.

effects. ${ }^{[177,183]}$ Their interplay is complex and optimizing one parameter (for example HTM conductivity to maximize fill factors) generally results in the deterioration of another parameter (for example the open-circuit voltage). Thus, devices incorporating only $t \mathrm{BP}$ and LiTFSI result in a suboptimal mixture that minimizes the overall losses.

Chemical oxidants such as $\mathrm{N}(\mathrm{PhBr})_{3} \mathrm{SbCl}_{6}{ }^{[71]}$ or tris $(2-(1 \mathrm{H}$ -pyrazol-1-yl)pyridine)cobalt(III) ${ }^{[19,185]}$ and protonic acid-induced p-doping of the $\mathrm{HTM}^{[186]}$ may be used to independently tune the HTM conductivity without affecting the $\mathrm{TiO}_{2}$ /dye interaction. This results in a clear path to device optimization and indeed, the current state-of-the-art ssDSSC includes a mixture of LiTFSI and chemical doping to achieve a power conversion efficiency of $7.2 \% .{ }^{[19]}$ With this understanding of the HTM requirements for high-performance dye-sensitized solar cells, it becomes clear why it has been difficult to find HTMs that 

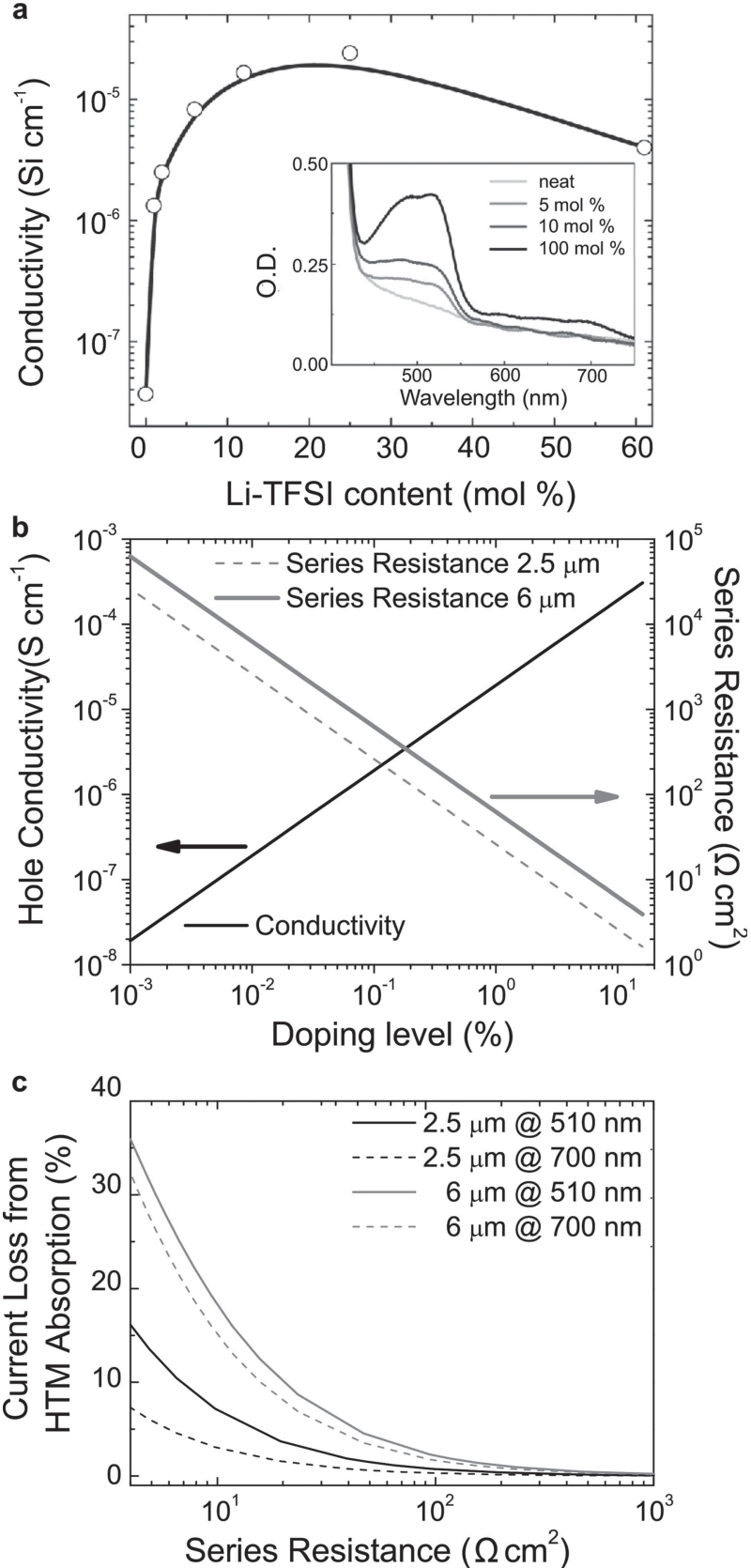

Figure 6. Absorption losses in doped spiro-OMeTAD-based DSSCs. a) Effect of Li-TFSI doping on conductivity and UV-vis light absorption of spiro-OMeTAD. b) Calculated hole conductivity and series resistance due to hole transport in $2.5 \mu \mathrm{m}$ (dotted grey line) and $6 \mu \mathrm{m}$ (solid grey line) thick ssDSSCs. c) Loss of photocurrent in Z907-sensitized sDSSCs by parasitic absoprtion for 2.5 and $6 \mu \mathrm{m}$-thick active layers. With increasing doping level, leading to a reduction in estimated series resistance, the photocurrent decreases dramatically, particularly for the thick ssDSSC. A mobility of $10^{-4} \mathrm{~cm}^{2} \mathrm{~V}^{-1} \mathrm{~s}^{-1}$ was assumed for these calculations, while optical parameters were obtained from literature. Note that a series resistance of less than $8 \Omega \mathrm{cm}^{2}$ is required for high fill factors and efficiencies. a) Reproduced with permission. ${ }^{[19]}$ Copyright 2013, Royal Society of Chemistry.

out-perform spiro-OMeTAD. Its highest occupied molecular orbital (HOMO) level is exactly right for the optimized balance between hole-transfer yield and open-circuit voltage, ${ }^{[187]}$ it allows facile and stable oxygen-induced doping in the presence of LiTFSI or other chemical oxidants, and it exhibits good pore infiltration. HTMs that most-closely rival the performance of spiroOMeTAD are very similar in structure, HOMO level, oxidation potential, and ability to fill the pores of mesoporous $\mathrm{TiO}_{2}$.

\subsection{Parasitic Absorption and Losses in Thick ssDSSCs}

While p-doping via oxidation of the HTMs is essential for optimized hole transport, it leads to another problem - parasitic absorption. Singly and doubly oxidized spiro-OMeTAD show a strong absorption band around $500 \mathrm{~nm}$ and a weaker one around $700 \mathrm{~nm}$ (Figure 6a). ${ }^{[179-181]}$

The extinction coefficients of these absorption bands have been quantified to be around 30000 and $6700 \mathrm{M}^{-1} \mathrm{~cm}^{-1}$ respectively. ${ }^{[164]}$ The oxidized HTM therefore competes with the dye for light absorption. ${ }^{[98]}$ This is particularly relevant for low extinction coefficient sensitizers, such as the widely used Z907 and N719 dyes. ${ }^{[188-190]}$ As shown in Figure 6b,c, there is a tradeoff between hole conduction and the parasitic absorption of the oxidized HTM, both of which increase with doping density. This may be one of the reasons why thicker $(5-7 \mu \mathrm{m})$ ssDSSCs currently do not generate high photocurrents.

Increasing the active layer thickness to maximize light harvesting has been one of the primary paradigms in ssDSSC research. It was initially believed that such thick devices could not be realized due to pore-filling limitations as discussed above. ${ }^{[75,162,163]}$ Past attempts in preparing thick ssDSSCs showed that the doping level of LiTFSI has to be further increased to minimize the series resistance. ${ }^{\text {75] }}$ This leads to a shift of the $\mathrm{TiO}_{2}$ surface potential and thus to a reduction in $V_{\mathrm{OC}}$ due to Li-TFSI being employed as the dopant. Furthermore, the increase in parasitic absorption seems to prevent the expected scaling of the photocurrent with device thickness. We have quantified the trade-off between improved conductivity (i.e., reduced series resistance) in the solar cell and light lost due to parasitic absorption at 510 and $700 \mathrm{~nm}$ here in Figure 6c. Another study has shown that series resistances below ca. $5-10 \Omega \mathrm{cm}^{2}$ are essential to keeping resistive power losses below $10 \%{ }^{[179]}$ It is therefore evident that new materials are required to improve light harvesting in ssDSSCs. One route is to develop transparent HTMs with higher intrinsic mobilities, thus requiring lower doping levels. An alternative route is the development of sensitizers with high extinction coefficients that do not require the preparation of thick active layers, as discussed in the following section.

\section{Alternative Sensitizers}

One of the main disadvantages of light-absorbing dyes in solidstate devices is that optimal performance is only achieved when a monolayer of dye is adsorbed onto the surface of the mesoporous oxide, ${ }^{[89,90]}$ creating the challenge of balancing a sufficiently high enough photoanode surface area with efficient charge transport across the metal oxide crystals. As discussed above, an increase of the thickness of the mesoporous layer 
does not, however, deliver the desired increase in photocurrent. The obvious solution to this conundrum is the use of absorber materials that have high molar extinction coefficients and perform effectively when more than a monolayer is deposited. The ability of a material to meet these requirements plays a crucial role in increasing the efficiency of solid-state devices to match, and even surpass, the efficiency of their liquid electrolyte-based counterparts. This search has led researchers to closely investigate inorganic absorber materials, and more recently, a family of organometallic halide perovskites.

The semiconductor-sensitized solar cell (SSSC) is a model example and can be subdivided into two major classes: the extremely thin absorber (ETA) solar cell[191,192] and the quantum-dot-sensitised solar cell (QDSSC). ${ }^{[193]}$ These types of solar cells typically utilize inorganic semiconducting materials as the light-absorber layer. Inorganic materials have many attractive features such as high molar extinction coefficients, ${ }^{[194]}$ high intrinsic carrier mobilities, ${ }^{[195]}$ large intrinsic dipole moments, and the opportunity to tune the bandgap of the absorber by exploiting quantum-size effects, or by compositional tuning. ${ }^{196,197]}$ Additionally, inorganic absorbers have increased thermodynamic and optical stability compared to organic or metal-organic dyes. In the light of such a plethora of advantages, ${ }^{[198-200]}$ it is no surprise that the replacement of organic dyes by inorganic semiconductors has been widely studied. ${ }^{[196,201-204]}$

One of the most crucial factors in achieving satisfactory device performance in SSSCs is obtaining a near complete, uniform coverage of the mesoporous photoanode. ${ }^{[205]}$ This has been achieved through chemical-bath deposition (CBD) ${ }^{[199,200,206-208]}$ and successive ionic-layer adsorption and reaction (SILAR). ${ }^{[209,210]}$ Increasing the thickness of the absorber layer in QDSSCs leads however to an increase in charge-carrier recombination. ${ }^{[211]}$ In the family of solution-processable ETA solar cells, one of the most promising absorbers is $\mathrm{Sb}_{2} \mathrm{~S}_{3}$ with reported conversion efficiencies of up to $6.3 \% .{ }^{[199]}$ In QDSSCs, the very short lifetime of the charge carriers in the material poses a major problem for efficient device operation, resulting in a large degree of recombination within the absorber layer. ${ }^{[212]}$

The solution to this problem is the utilization of a material which absorbs strongly in most of the visible region and has long charge-carrier lifetimes. Such a material has recently been found in the family of organometallic halide perovskites. The methylammonium lead trihalides emerged as an excellent absorber material for ETA solar cells, showing long chargecarrier lifetimes ${ }^{[213,214]}$ as well as strong absorption over most of the visible spectrum. ${ }^{[215]}$ The fascinating properties of this material also seem to negate the need for a separate electronconducting material since it was shown to be a very efficient electron transporter. ${ }^{[215-218]}$ This allowed the fabrication of ETA solar cells that use inert scaffolds such as alumina and zirconia, reaching efficiencies of up to $10.9 \% .^{[215,219]}$ This type of device is most commonly known as the meso-superstructured solar cell (MSSC). Its operating principles are shown in Figure 7.

This class of perovskite can be deposited in a variety of ways, the most common of which are spin-coating and sequential deposition. Recently, using the sequential-deposition method on mesoporous $\mathrm{TiO}_{2}$, Burschka et al. have reported devices with $15 \%$ power conversion efficiency for a perovskite-sensitized hybrid solar cell that otherwise resembles the traditional ssDSSC device architecture. ${ }^{[20]}$ Going beyond MSSCs, perovskite solar cells have also been shown to function in a planar heterojunction, achieving a maximum conversion efficiency of $15.4 \%$. ${ }^{213,217,218,220]}$

It is important to note that the highly reactive nature of the liquid electrolytes precludes the possibility of their application with the more sensitive inorganic absorbers. Corrosion or complete dissolution of the absorber layer has been reported. ${ }^{[203,206,221-224]}$ Although the ETA and QDSSC approach yield high efficiencies, it appears that for the best solutionprocessed semiconductors, mesoporous architecture is not necessary. ${ }^{[198,217,220,225,226]}$ Hence, we expect much more future activity on solution-processed thin-film planar-heterojunction solar cells.

\section{Stability}

We have so far discussed the performance of DSSCs, ssDSSCs and all-solid-state hybrid solar cells. Nevertheless, it will ultimately be their stability (i.e. their lifetime under operation) that will determine whether these device platforms are just interesting photovoltaic concepts or viable technologies. Solar-cell stability is a measure of whether a given technology can withstand long-term exposure to the conditions relevant to solar cell use, such as high illumination, temperature, or humidity. Here, we will separately address the stability issues for the three main device components: sensitizer, mesoporous anode, and hole transporter.

Note that the conditions under which the long-term stability of a solar cell is tested are extremely important and it is imperative to clearly specify the precise testing protocol. Factors such as ultraviolet light (UV) exposure, type of encapsulation, and continuous versus intermittent solar irradiation are often not clearly described, even though they can have profound effects on the apparent stability of solar cells employing solid-state hole transporters. ${ }^{[19,215,227-229]}$ UV cut-off filters are often employed, but the exact nature of the effect of UV light on solar-cell stability is not yet well understood. ${ }^{[19,215,227-229]}$

Sensitizer stability In order to achieve sufficient stability to withstand 25 years under illumination, sensitizers must be able to complete over 108 turnovers before decomposing. ${ }^{[230,231]}$ This is in principle realistic for ruthenium-based dyes, as determined by spectroscopic studies, ${ }^{[231]}$ although there is some debate over whether these results hold under real operating conditions for commonly used Ru-based sensitizers. ${ }^{[232,233]}$ We point out that apparent dye stability is a result of ultrafast electron injection that out-competes degradation mechanisms. ${ }^{[230-232]}$ To achieve such fast electron transfer, the excited state energy of the sensitizer must lie significantly above the $\mathrm{TiO}_{2}$ acceptor states, but this comes at the cost of a loss in potential. Ideally, new-generation dyes should have lower excited-state levels while at the same time exhibiting longer excited state lifetimes, allowing efficient charge generation. ${ }^{[15]}$ The stability of these dyes will however have to be carefully tested to ensure that the injection still out-competes degradation. ${ }^{[231]}$ 
a
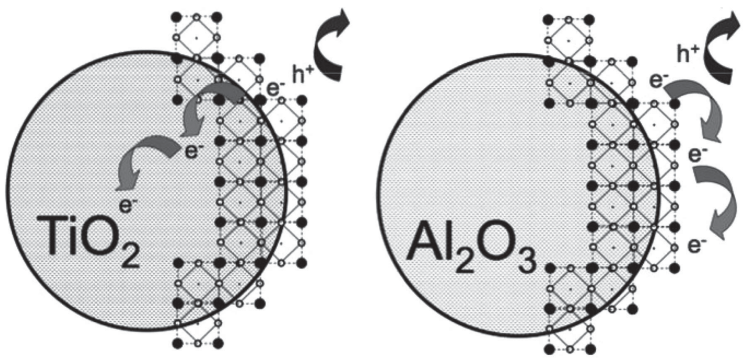

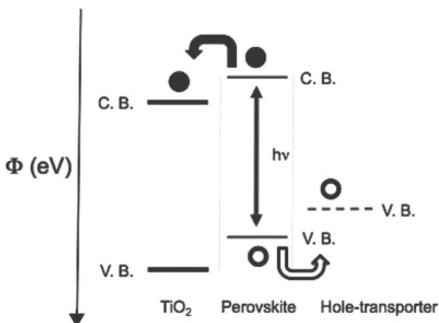

с.в.
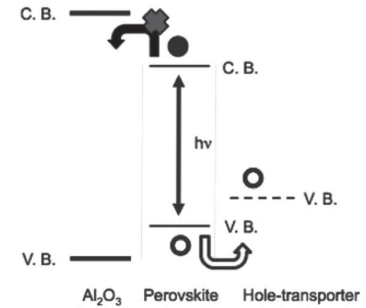

b

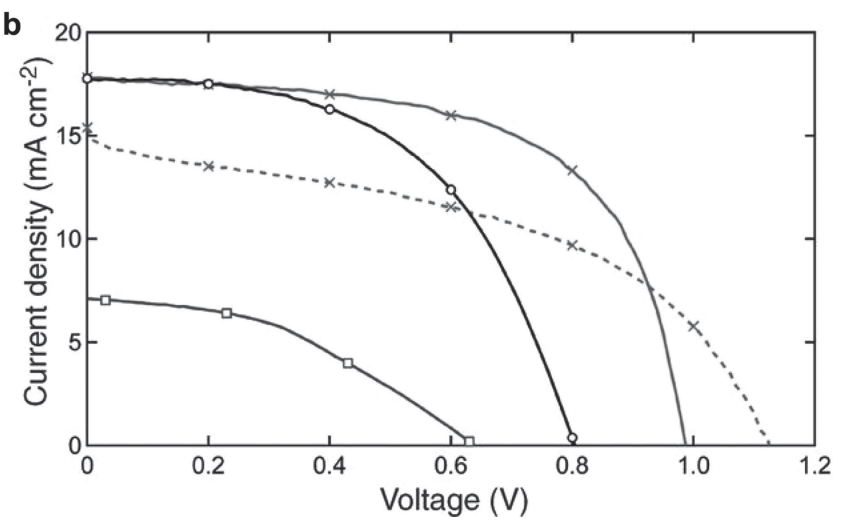

Figure 7. a) Schematic illustrating the charge transfer and charge transport in a perovskite-sensitized $\mathrm{TiO}_{2}$ solar cell (left) and a noninjecting $\mathrm{Al}_{2} \mathrm{O}_{3}$-based solar cell (right); a representation of the energy landscape is shown below, with electrons shown as solid circles and holes as open circles. b) Current-density-voltage characteristics under simulated AM1.5 $100 \mathrm{~mW} \mathrm{~cm}{ }^{-2}$ illumination for $\mathrm{Al}_{2} \mathrm{O}_{3}$-based devices, one exhibiting high efficiency (grey solid trace with crosses) and one exhibiting $V_{O C}>1.1 \mathrm{~V}$ (dashed line with crosses); for a perovskite-sensitized $\mathrm{TiO}_{2}$ solar cell (black trace with circles); and for a planar-junction diode with structure FTO/compact $\mathrm{TiO}_{2} / \mathrm{CH}_{3} \mathrm{NH}_{3}$ Pbl3-x $\mathrm{Cl}_{x}$ /spiro-OMeTAD/Ag (dark grey trace with squares). Adapted with permission. ${ }^{[215]}$ Copyright 2012, American Association for the Advancement of Science.

\subsection{Mesoporous Photoanode Stability}

The sensitivity of mesoporous $\mathrm{TiO}_{2}$ to UV exposure has recently been identified as the initial cause for instability of ssDSSCs. ${ }^{[234]}$ $\mathrm{TiO}_{2}$ nanoparticles possess surface defects (oxygen vacancies) that are known to interact with both water and oxygen in the atmosphere. ${ }^{[235-238]}$ They give rise to electronic defect states that are located $0.7-1 \mathrm{eV}$ below the $\mathrm{TiO}_{2}$ conduction band, depending on the chemistry of the crystal surface. ${ }^{[238-242]}$ Molecular oxygen from the atmosphere pacifies these trap sites by binding to the $\mathrm{Ti}^{3+}$ sites. ${ }^{[237,238,242]}$ However, when encapsulated under nitrogen, UV illumination removes the pacifying oxygen, resulting in rapid device degradation (Figure 8). ${ }^{\text {[234] }}$ Encapsulated UV exposed solar cells therefore suffer from the formation of a great number of deep trap sites, enabling a significant loss pathway through recombination with holes in the HTM. ${ }^{[19,142,179,243,244]}$ We point out that this degradation process is reversible upon exposure of the solar cells to air in the dark, demonstrating that no permanent chemical change takes place in any of the solar-cell components. ${ }^{[234]}$

This presents a conundrum, as the organic dyes and HTMs used in ssDSSCs are unstable in the presence of oxygen and moisture. ${ }^{[215,227,245-247]}$ While it is possible to employ a UV filter to cut-out wavelengths below approximately $420 \mathrm{~nm}$, as has been done in previous reports of long-term ssDSSC stability, ${ }^{[19,20]}$ this is expensive and results in a loss in current arising from light absorption in this spectral range. Very recently, chemical-bath deposition of alumina ${ }^{[248]}$ was shown to very efficiently pacify oxygen vacancies and enhance the lifetimes of sealed devices. Interstitial substitution of Ti adjacent to oxygen defect sites with Al permanently pacifies these defects, significantly enhancing the lifetime of sealed devices.

DSSCs employing liquid electrolytes do not show such a high sensitivity to UV-light exposure. ${ }^{[249,250]}$ This is likely to be due to acetonitrile (the solvent commonly used for the electrolyte) pacifying deep trap sites itself. UPS studies demonstrated that the availability of these states is strongly diminished in the presence of acetonitrile. ${ }^{[239,240]}$ 4-tert-butylpyridine, a common additive in both solid- and liquid-state dye-sensitized solar cells, has also been demonstrated to pacify deep oxygen vacancy sites. ${ }^{[251]}$ It appears that these additives can bind to the defect sites, pacifying them in a similar way as molecular oxygen, thus preventing the losses described above. Another path to overcoming this light-induced instability is the surface manipulation of the mesoporous $\mathrm{TiO}_{2}$ anode to prevent, suppress, or stably pacify the deep vacancy sites.

\subsection{Hole-Transporting Material Stability}

Triiodide-based electrolytes have been shown to photobleach under prolonged ultraviolet light exposure, hindering longterm stability. ${ }^{[4,249]}$ These issues are thoroughly addressed in reviews by Kroon et al. ${ }^{[46]}$ and Hinsch et al. ${ }^{[249]}$ and have been largely resolved by the introduction of low volatility solvents such as valeronitrile, and $\mathrm{MgI}_{2}$ additives which prevent the photobleaching of the redox couple. Stable solar-cell performance was observed under operating conditions for over $1000 \mathrm{~h}$, while stable photocurrents were observed for $10000 \mathrm{~h}$ by choosing hydrophobic dyes, excluding water from the electrolyte. ${ }^{[46,249]}$ Solvent-free dye-sensitized solar cells based on eutectic melts such as 1-propyl-3-methylimidazolium iodide, 1-ethyl-3-methylimidazolium iodide, 1,3-dimethylimidazolium iodide, and mixtures of these, have also been introduced to circumvent these issues, reaching remarkable PCEs of over 7\%. ${ }^{[252,253]}$ These devices display vastly improved long-term stability (Figure 8a) over $1000 \mathrm{~h}$ under 1 sun illumination at $60{ }^{\circ} \mathrm{C}$. We note that DSSCs employing these alternative electrolyte compositions exhibit significantly lower performances than current state-of-the-art DSSCs. The newer high-performance cobalt-based redox couples ${ }^{[33]}$ still have to demonstrate long-term stability, which do not yet reach stable performance of over $100 \mathrm{~h}$ under constant illumination at room temperature. ${ }^{254]}$ 

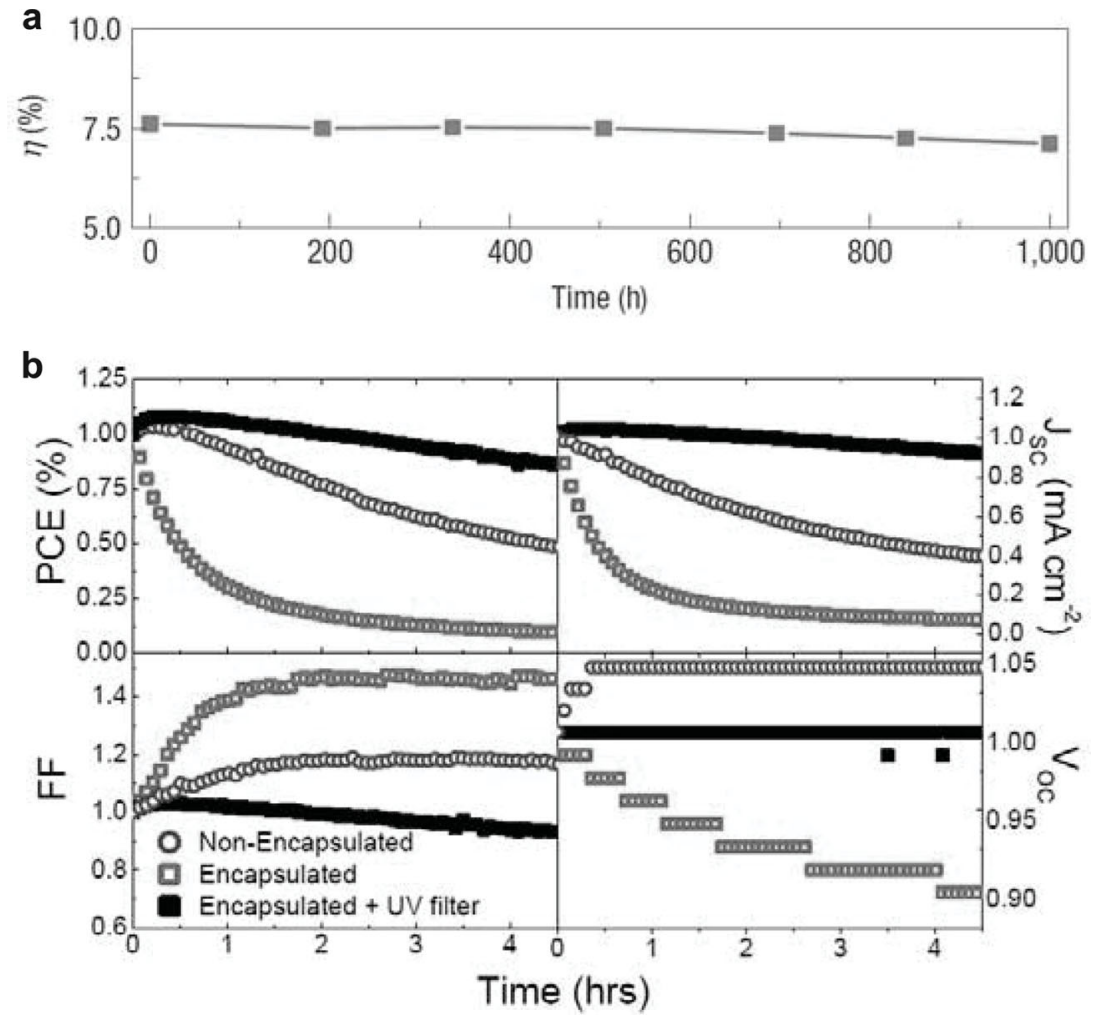

Figure 8. Stability of ssDSSCs. Comparison of devices employing: a) a stable ionic liquid "gel" PMII electrolyte and b) ssDSSCs using spiro-OMeTAD as the HTM under full AM 1.5C sun illumination. In (b), the open squares correspond to solar cells that were encapsulated with epoxy in a nitrogen-filled glovebox, the solid squares to similar encapsulated cells under a $<420$ cut-off UV filter, and the open circles correspond to non-encapsulated cells tested under ambient conditions. a) Adapted with permission. ${ }^{[253]}$ Copyright 2008, Nature Publishing Group. b) Adapted with permission. ${ }^{[234]}$ Copyright 2013, Nature Publishing Group.

ssDSSCs were initially introduced to remove the leakage and corrosion issues intrinsic to the liquid electrolyte-based devices. While all-solid-state hybrid devices have shown substantial improvements in cell performance, with $7.2 \%$ for the dye-sensitized system ${ }^{[19]}$ and $15 \%$ for perovskite-sensitized devices, ${ }^{[20]}$ surprisingly few studies have been published on their longterm stability. ${ }^{[19,227-229,255]}$ The main degradation of the HTMs used in SsDSSCs similar to organic photovoltaic devices, ${ }^{[256-260]}$ is probably the oxidation of the hole transporter after prolonged exposure to air. ${ }^{[74,98,177-181]}$ The same may also apply to the dyes, since pore filling of the HTM is usually not complete ${ }^{[111,163,165]}$ and oxygen can hence interact with the excited dyes. ${ }^{[256-260]}$ As a result, proper encapsulation is absolutely critical for the longterm stability of sSDSSCs. A dilemma arises from the fact that conventional ssDSSCs benefit from oxygen-induced p-doping of the HTM as described in Section 4. ${ }^{74,98,177-181]}$ While the oxidation products are stable on short term, there is a lack of studies on long-term stability of this doping mechanism when the solar cells are exposed to light and increased temperatures in the absence of oxygen. Furthermore, the lithium-induced reaction does not reach completion, and atmospheric conditions are likely to affect the degree to which the HTM is oxidized. ${ }^{[74,98,177-181]}$ Long-term stability is therefore another motivation for the further development of non-reversible chemical doping. Another stability concern is morphological changes in the HTM upon long exposure to both light and high temperatures. The most-common HTMs have been shown to be amorphous, ${ }^{[71]}$ yet crystallization of the HTM inside the pores could affect the contact to the dye as well as hole transport.

Burschka et al. have published stability data of both dye-sensitized solar cells and perovskite-sensitized solar cells..$^{19,20,228]}$ The standard ssDSSCs, employing a cobalt dopant and encapsulated in a nitrogen filled glovebox, maintained $80 \%$ of their initial power conversion efficiency after 40 days under AM $1.5100 \mathrm{~mW} \mathrm{~cm}{ }^{-2}$ solar illumination, when a UV cut-off filter $(<420 \mathrm{~nm})$ was used. ${ }^{[19]}$ More recently, they have demonstrated that the performance of perovskitesensitized $\mathrm{TiO}_{2}$-based solar cells remains at $80 \%$ of the initial value under approximately $100 \mathrm{~mW} \mathrm{~cm}{ }^{-2}$ of white LED light at $40{ }^{\circ} \mathrm{C}$, again in the absence of any UV light $(<420 \mathrm{~nm}){ }^{[20]}$ However, even without a UV component to the light source, a shunt in the current-voltage curve was emerging after $1000 \mathrm{~h}$ exposure to light. ${ }^{[20]}$ Other studies have also demonstrated that achieving longterm stability in ssDSSCs is far from straightforward, and indeed, exposure to UV light must be avoided. ${ }^{[19,215,227-229]}$ In light of the atmospheric sensitivity of these devices, the encapsulation and measurement procedures should be described in detail. Clearly, significant effort is required to suitably stabilize the ssDSSCs based on mesoporous $\mathrm{TiO}_{2} \cdot{ }^{[234]}$

\section{Future Directions for Solution-Processed All-Solid-State Devices}

Sensitized solar cells are very promising candidates for lowcost solar energy generation and represent an extremely rich research platform for investigating optoelectronic processes in organic, inorganic and hybrid semiconductor materials. In this review we have identified three critical aspects that need to be addressed in order to achieve competitive power conversion efficiencies and long-term stability:

1. Reduce fill factor losses

2. Reduce losses in potential

3. Reduce light-absorption losses

The first limitation arises in part from the series resistance of the DSSC components, from the recombination of electrons in the TCO with vacancies in the donor species and from charge-carrier recombination at the mesoporous metal oxide/ HTM interface. As pointed out by Zhu and co-workers, ${ }^{[54]}$ it is not enough to achieve near-unity charge collection efficiencies at working conditions. Recombination losses must be minimized or transport must be maximized in order to improve 
the fill factor of the solar cell. We have shown that conventional approaches to intricately control the morphology of the photoanodes in order to improve transport properties (e.g., block-copoylmer-assisted templating, hierarchical assemblies or anodized nanotubes) do not necessarily lead to higher performing devices. Electronic disorder appears to be the root cause of the charge-transport limitations, and indeed open-circuit limitations in the mesoporous oxide. These limitations can be minimized by employing extended crystalline systems, ${ }^{[137]}$ such as nanowires. ${ }^{[146]}$ An ideal photoanode should combine a favourable morphology for dye adsorption with a minimization of electronic disorder. In other words, such a photoanode should consist of a single-crystalline structure, exhibiting a tunable and accessible network of pores and a high surface area. Mesoporous single crystals have recently been demonstrated, and provide an exciting new route towards further technological improvements. Once the charge transport in the anode is accelerated, the devices will be limited by hole transport, which in solid state DSSCs is determined by the doping level, as discussed in Section 4. ${ }^{[74,98,177-181]}$ This is already relevant in the current generation of devices at the high charge densities present at maximum power conditions, demonstrating that both electron and hole transport should be accelerated to improve the device fill factors.

The second limitation can be reduced to a large extent by replacing the iodine redox couple with a one-electron regeneration system, either an alternative redox couple or a solidstate hole transporter. To date, the performance of solid-state devices lags behind liquid electrolyte-based DSSCs when dyesensitizers are used. The main limitation in these devices arises from thickness constraints due to the combination of parasitic absorption and poor charge transport. Unfortunately, these issues are intertwined: in order to reduce series resistance losses, the hole transporter must be oxidized to achieve high conductivities; but oxidized hole transporters exhibit absorption bands that overlap with dye absorption, thus reducing the overall light absorption in the films. It is therefore evident that new materials are required in order to improve lightharvesting in ssDSSCs. One route is the development of transparent HTMs with higher intrinsic mobilities, thus requiring lower doping levels. It is important to note that the inorganic absorber approach has proven to not require a mesoporous n-type metal oxide photoanode, making it less relevant for solid-state-sensitized solar cells.

The third limitation is a convolution of the previous two. DSSCs are fundamentally handicapped by the requirement of the use of a monolayer of the sensitizer covering the mesoporous metal oxide in order to achieve maximum performance. ${ }^{89,90]}$ As a consequence, the mesoporous photoanode needs to be thick in order to maximize light absorption. Thicker films, however, suffer from increasingly large losses due to dark current processes. Thus, optimized devices walk the fine line between maximizing light absorption in the thinnest possible layer. A very promising approach incorporates inorganic absorbers which bypass the problem altogether as they function efficiently even when more than a monolayer is deposited in the mesoporous structure. Solid-state hybrid solar cells incorporating organometallic absorbers have taken this concept to the next level, promising to achieve power conversion efficiencies that rival the very best established thin film technologies. Further improvements in contact optimization are expected to yield devices exceeding $20 \%$ power conversion efficiencies in the near future.

While relatively promising results have been obtained in DSSCs employing liquid and ionic-liquid electrolytes, the stability of the solid-state DSSCs is far from proven. This is important because the solid-state DSSC is considered to be a more promising technology regarding both stability and theoretically attainable efficiency. However, these solar cells appear to suffer from a rapid deterioration in performance when encapsulated and exposed to UV light. ${ }^{[234]}$ Overcoming UV-light instability of sensitized $\mathrm{TiO}_{2}$ is an important aspect that still needs to be explored. The removal of the UV component of the solar spectrum, however, results in good stability during $1000 \mathrm{~h}$ lightsoaking experiments. ${ }^{[19,20]}$ Still, significant research efforts will be required to understand the stability of the organic HTMs and mesoporous n-type oxide scaffolds under UV light for this technology to be ready for commercialization.

To conclude, the solid-state dye-sensitized solar cell, through the extremely thin absorber approach, has led to the birth of a new photovoltaic technology based on organometallic halide perovskite absorbers. However, there remains significant scope for colourful semitransparent dye-sensitized solar cells based on organic and metal complex sensitizers for a broad range of applications. There also remains much scope for further fundamental studies of photoinduced charge generation at hybrid interfaces.

\section{Acknowledgements}

P. Docampo, S. Guldin, and T. Leijtens contributed to this work equally. The research leading to the results presented here was partly funded by the European Union Seventh Framework Programme [FP7/20072013] under grant agreement 316494. S.G. is grateful for support by the German National Academy of Sciences Leopoldina, Fellowship LPDS2012-13. N.N. acknowledges funding by the Government of the Republic of Trinidad and Tobago.

Received: January 29, 2014 Revised: February 20, 2014 Published online:

[1] N. Oreskes, Science 2004, 306, 1686.

[2] N. Stern, The Economics of Climate Change: The Stern Review, Cambridge University Press, New York 2007.

[3] K. Anderson, A. Bows, Philos. Trans. R. Soc. A 2011, 369, $20-44$.

[4] N. S. Lewis, D. G. Nocera, Proc. Natl. Acad. Sci. 2006, 103, 15729-15735.

[5] M. Green, K. Emery, Y. Hishikawa, W. Warta, E. Dunlop, Prog. Photovoltaics 2013, 21, 1-11.

[6] V. M. Fthenakis, H. C. Kim, Sol. Energy 2011, 85, 1609-1628.

[7] E. A. Alsema, Prog. Photovoltaics 2000, 8, 17-25.

[8] V. M. Fthenakis, H. C. Kim, E. Alsema, Environ. Sci. Technol. 2008, 42, 2168-2174.

[9] J. Peng, L. Lu, H. Yang, Renewable Sustainable Energy Rev. 2013, 19 , 255-274.

[10] G. Li, V. Shrotriya, J. Huang, Y. Yao, T. Moriarty, K. Emery, Y. Yang, Nat. Mater. 2005, 4, 864-868. 
[11] S. McDonald, G. Konstantatos, S. Zhang, P. Cyr, E. Klem, L. Levina, E. Sargent, Nat. Mater. 2005, 4, 138-U14.

[12] H. Katagiri, K. Jimbo, W. S. Maw, K. Oishi, M. Yamazaki, H. Araki, A. Takeuchi, Thin Solid Films 2009, 517, 2455-2460.

[13] S. Jeong, B.-S. Lee, S. Ahn, K. Yoon, Y.-H. Seo, Y. Choi, B.-H. Ryu, Energy Environ. Sci. 2012, 5, 7539-7542.

[14] F. C. Krebs, T. Tromholt, M. Jorgensen, Nanoscale 2010, 2, 873-886.

[15] H. Snaith, Adv. Funct. Mater. 2010, 20, 13-19.

[16] G. Hashmi, K. Miettunen, T. Peltola, J. Halme, I. Asghar, K. Aitola, M. Toivola, P. Lund, Renewable Sustainable Energy Rev. 2011, 15, 3717-3732.

[17] E. Crossland, N. Noel, T. Leijtens, V. Sivaram, J. Alexander-Webber, H. Snaith, Nature 2013, 495, 215-219.

[18] T. Yamaguchi, N. Tobe, D. Matsumoto, T. Nagai, H. Arakawa, Sol. Energy Mater. Sol. Cells 2010, 94, 812-816.

[19] J. Burschka, A. Dualeh, F. Kessler, E. Baranoff, N.-L. Cevey-Ha, C. Yi, M. Nazeeruddin, M. Grätzel, J. Am. Chem. Soc. 2011, 133, 18042-18045.

[20] J. Burschka, N. Pellet, S.-J. Moon, R. Humphry-Baker, P. Gao, M. K. Nazeeruddin, M. Grätzel, Nature 2013, 499, 316-319.

[21] M. Grätzel, Prog. Photovoltaics 2000, 8, 171-185.

[22] J. Moser, Monatsh. Chem. 1887, 8, 373

[23] R. Nelson, J. Phys. Chem. 1965, 69, 714-718.

[24] S. Namba, Y. Hishiki, J. Phys. Chem. 1965, 69, 774-779.

[25] K. Hauffe, H. Danzmann, H. Pusch, J. Range, H. Volz, J. Electrochem. Soc. 1970, 117, 993.

[26] B. O'Regan, M. Grätzel, Nature 1991, 353, 737-740.

[27] W. Shockley, H. Queisser, J. Appl. Phys. 1961, 32, 510-519.

[28] M. Nazeeruddin, A. Kay, I. Rodicio, R. Humphry-Baker, E. Muller P. Liska, N. Vlachopoulos, M. Grätzel, J. Am. Chem. Soc. 1993, $115,6382-6390$

[29] M. Nazeeruddin, S. Zakeeruddin, R. Humphry-Baker, M. Jirousek, P. Liska, N. Vlachopoulos, V. Shklover, C. Fis-cher, M. Grätzel, Inorg. Chem. 1999, 38, 6298-6305.

[30] M. Nazeeruddin, P. Pechy, T. Renouard, S. Zakeeruddin R. Humphry-Baker, P. Comte, P. Liska, L. Cevey, E. Costa, V. Shklover, L. Spiccia, G. Deacon, C. Bignozzi, M. Grätzel, J. Am. Chem. Soc. 2001, 123, 1613-1624.

[31] M. Grätzel, J. Photochem. Photobiol. C 2003, 4, 145-153.

[32] Y. Chiba, A. Islam, Y. Watanabe, R. Komiya, N. Koide, L. Han, Jpn. J. Appl. Phys. 2006, 45, L638-L640.

[33] A. Yella, H.-W. Lee, H. Tsao, C. Yi, A. Chandiran, M. Nazeeruddin, E.-G. Diau, C.-Y. Yeh, S. Zakeeruddin, M. Grätzel, Science 2011, 334, 629-634.

[34] A. Hagfeldt, M. Grätzel, Acc. Chem. Res. 2000, 33, 269-277.

[35] G. Benko, J. Kallioinen, J. Korppi-Tommola, A. Yartsev, V. Sundstrom, J. Am. Chem. Soc. 2002, 124, 489-493.

[36] P. Barnes, L. Liu, X. Li, A. Y. Anderson, H. Kisserwan, T. Ghaddar, J. Durrant, B. O'Regan, Nano Lett. 2009, 9, 3532-3538.

[37] Q. Wang, S. Ito, M. Grätzel, F. Fabregat-Santiago, I. Mora-Sero, J. Bisquert, T. Bessho, H. Imai, J. Phys. Chem. B 2006, 110, 25210-25221.

[38] S. Haque, Y. Tachibana, D. Klug, J. Durrant, J. Phys. Chem. B 1998 $102,1745-1749$

[39] A. Hagfeldt, G. Boschloo, L. Sun, L. Kloo, H. Pettersson, Chem. Rev. 2010, 110, 6595-6663.

[40] A. Hauch, A. Georg, Electrochim. Acta 2001, 46, 3457-3466.

[41] N. Papageorgiou, W. Maier, M. Grätzel, J. Electrochem. Soc. 1997, 144, 876-884.

[42] S. Haque, Y. Tachibana, R. Willis, J. Moser, M. Grätzel, D. Klug, J. Durrant, J. Phys. Chem. B 2000, 104, 538-547.

[43] J. van de Lagemaat, N. Park, A. Frank, J. Phys. Chem. B 2000, 104, 2044-2052.

[44] A. Zaban, M. Greenshtein, J. Bisquert, ChemPhysChem 2003, 4, 859-864.
[45] M. Grätzel, Acc. Chem. Res. 2009, 42, 1788-1798.

[46] J. Kroon, N. Bakker, H. Smit, P. Liska, K. Thampi, P. Wang, S. Zakeeruddin, M. Grätzel, A. Hinsch, S. Hore, U. Würfel, R. Sastrawan, J. Durrant, E. Palomares, H. Pettersson, T. Gruszecki, J. Walter, K. Skupien, G. Tulloch, Prog. Photovoltaics 2007, 15, 1-18.

[47] M. Grätzel, Prog. Photovoltaics 2006, 14, 429-442.

[48] S. Yoon, S. Tak, J. Kim, Y. Jun, K. Kang, J. Park, Build. Environ. 2011 46, 1899-1904.

[49] L. Peter, Phys. Chem. Chem. Phys. 2007, 9, 2630-2642.

[50] P. Cameron, L. Peter, S. Hore, J. Phys. Chem. B 2005, 109, 930-936.

[51] F. Fabregat-Santiago, J. Bisquert, G. Garcia-Belmonte, G. Boschloo, A. Hagfeldt, Sol. Energy Mater. Sol. Cells 2005, 87, 117-131.

[52] A. Frank, N. Kopidakis, J. van de Lagemaat, Coord. Chem. Rev. 2004, 248, 1165-1179.

[53] B. O'Regan, J. Durrant, Acc. Chem. Res. 2009, 42, 1799-808.

[54] K. Zhu, S.-R. Jang, A. J. Frank, J. Phys. Chem. Lett. 2011, 2, 1070-1076.

[55] S. Ito, P. Liska, P. Comte, R. Charvet, P. Pechy, U. Bach, L. Schmidt-Mende, S. M. Zakeeruddin, A. Kay, M. K. Nazeeruddin, M. Grätzel, Chem. Commun. 2005, 4351-4353.

[56] H. Nusbaumer, J.-E. Moser, S. M. Zakeeruddin, M. K. Nazeeruddin, M. Grätzel, J. Phys. Chem. B 2001, 105, 10461-10464.

[57] S. M. Feldt, E. A. Gibson, E. Gabrielsson, L. Sun, G. Boschloo, A. Hagfeldt, J. Am. Chem. Soc. 2010, 132, 16714-16724.

[58] S. A. Sapp, C. M. Elliott, C. Contado, S. Caramori, C. A. Bignozzi, J. Am. Chem. Soc. 2002, 124, 11215-11222.

[59] B. A. Gregg, F. Pichot, S. Ferrere, C. L. Fields, J. Phys. Chem. B 2001, 105, 1422-1429.

[60] T. Daeneke, T.-H. Kwon, A. B. Holmes, N. W. Duffy, U. Bach, L. Spiccia, Nat. Chem 2011, 3, 211-215.

[61] Y. Bai, Q. Yu, N. Cai, Y. Wang, M. Zhang, P. Wang, Chem. Commun. 2011, 47, 4376-4378.

[62] S. Hattori, Y. Wada, S. Yanagida, S. Fukuzumi, J. Am. Chem. Soc 2005, 127, 9648-9654.

[63] Z. Zhang, P. Chen, T. Murakami, S. Zakeeruddin, M. Grätzel, Adv. Funct. Mater. 2008, 18, 341-346.

[64] M. Wang, N. Chamberland, L. Breau, J.-E. Moser R. Humphry-Baker, B. Marsan, S. M. Zakeeruddin, M. Grätzel, Nat. Chem. 2010, 2, 385-389.

[65] H. Tian, Z. Yu, A. Hagfeldt, L. Kloo, L. Sun, J. Am. Chem. Soc. 2011, 133, 9413-9422.

[66] F. Hao, P. Dong, Q. Luo, J. Li, J. Lou, H. Lin, Energy Environ. Sci. 2013, 6, 2003-2019.

[67] B. E. Hardin, H. J. Snaith, M. D. McGehee, Nat. Photonics 2012 6, 162-169.

[68] J. W. Ondersma, T. W. Hamann, Coordin. Chem. Rev. 2013, 257, 1533-1543.

[69] L. JianFeng, B. Jie, X. XiaoBao, L. ZhiHong, C. Kun, C. Jin, W. MingKui, Chin. Sci. Bull. 2012, 57, 4131.

[70] K. Murakoshi, R. Kogure, Y. Wada, S. Yanagida, Chem. Lett. 1997 26, 471-472

[71] U. Bach, D. Lupo, P. Comte, J. E. Moser, F. Weissörtel, J. Sal-beck, H. Spreitzer, M. Grätzel, Nature 1998, 395, 583-585.

[72] J. E. Kroeze, N. Hirata, L. Schmidt-Mende, C. Orizu, S. D. Ogier, K. Carr, M. Grätzel, J. R. Durrant, Adv. Funct. Mater. 2006, 16 1832-1838.

[73] H. J. Snaith, S. M. Zakeeruddin, Q. Wang, P. Pechy, M. Grätzel, Nano Lett. 2006, 6, 2000-2003.

[74] A. Abrusci, I.-K. Ding, M. Al-Hashimi, T. Segal-Peretz, M. D. McGehee, M. Heeney, G. L. Frey, H. J. Snaith, Energy Environ. Sci. 2011, 4, 3051-3058.

[75] T. Leijtens, I.-K. Ding, T. Giovenzana, J. T. Bloking, M. D. McGehee, A. Sellinger, ACS Nano 2012, 6, 1455-1462. 
[76] C.-Y. Hsu, Y.-C. Chen, R. Y. -Y. Lin, K.-C. Ho, J. T. Lin, Phys. Chem. Chem. Phys. 2012, 14, 14099-14109.

[77] A. Sepehrifard, B. A. Kamino, T. P. Bender, S. Morin, ACS Appl. Mater. Interfaces 2012, 4, 6211-6215.

[78] G. Grancini, R. S. S. Kumar, A. Abrusci, H.-L. Yip, C.-Z. Li, A.-K. Y. Jen, G. Lanzani, H. J. Snaith, Adv. Funct. Mater. 2012, 22, 2160-2166.

[79] M. Planells, A. Abate, D. J. Hollman, S. D. Stranks, V. Bharti, J. Gaur, D. Mohanty, S. Chand, H. J. Snaith, N. Robertson, J. Mater. Chem. A 2013, 1, 6949-6960.

[80] L. Yang, B. Xu, D. Bi, H. Tian, G. Boschloo, L. Sun, A. Hagfeldt, E. M. J. Johansson, J. Am. Chem. Soc. 2013, 135, 7378-7385.

[81] Z. Wang, H. Kawauchi, T. Kashima, H. Arakawa, Coordin. Chem. Rev. 2004, 248, 1381-1389.

[82] J.-H. Yum, E. Baranoff, S. Wenger, M. Nazeeruddin, M. Grätzel, Energy Environ. Sci. 2011, 4, 842-857.

[83] A. Mihi, H. Miguez, J. Phys. Chem. B 2005, 109, 15968-15976.

[84] S. Guldin, S. Hüttner, M. Kolle, M. Welland, P. Müller-Buschbaum, R. Friend, U. Steiner, N. Tetreault, Nano Lett. 2010, 10, 2303-2309.

[85] M. Calvo, S. Colodrero, N. Hidalgo, G. Lozano, C. Lopez-Lopez, O. Sanchez-Sobrado, H. Miguez, Energy Environ. Sci. 2011, 4, 4800-4812.

[86] C. Hagglund, M. Zach, B. Kasemo, Appl. Phys. Lett. 2008, 92, 013113.

[87] S. D. Standridge, G. C. Schatz, J. T. Hupp, J. Am. Chem. Soc. 2009, 131, 8407-8409.

[88] M. D. Brown, T. Suteewong, R. S. S. Kumar, V. D'Innocenzo, A. Petrozza, M. M. Lee, U. Wiesner, H. J. Snaith, Nano Lett. 2011, $11,438-445$.

[89] A. Khazraji, S. Hotchandani, S. Das, P. Kamat, J. Phys. Chem. B 1999, 103, 4693-4700

[90] J.-H. Yum, P. Chen, M. Grätzel, M. K. Nazeeruddin, ChemSusChem 2008, 1, 699-707.

[91] T. Dittrich, E. Lebedev, J. Weidmann, Phys. Status Solidi A 1998, 1998, R5-R6.

[92] S. Burnside, V. Shklover, C. Barbé, P. Comte, F. Arendse, K. Brooks, M. Grätzel, Chem. Mater. 1998, 10, 2419-2425.

[93] K. Benkstein, N. Kopidakis, J. van de Lagemaat, A. Frank, J. Phys. Chem. B 2003, 107, 7759-7767.

[94] H. Snaith, L. Schmidt-Mende, Adv. Mater. 2007, 19, 3187-3200.

[95] H. Tang, K. Prasad, R. Sanjines, P. Schmid, F. Levy, J. Appl. Phys. 1994, 75, 2042-2047.

[96] P. Tiwana, P. Parkinson, M. Johnston, H. Snaith, L. Herz, J. Phys. Chem. C 2010, 114, 1365-1371.

[97] P. Tiwana, P. Docampo, M. Johnston, H. Snaith, L. Herz, ACS Nano 2011, 5, 5158-5166.

[98] T. Leijtens, J. Lim, J. Teuscher, T. Park, H. J. Snaith, Adv. Mater. 2013, 25, 3227-3233.

[99] K. Keis, E. Magnusson, H. Lindstrom, S. Lindquist, A. Hagfeldt, Sol. Energy Mater. Sol. Cells 2002, 73, 51-58.

[100] Q. Zhang, C. S. Dandeneau, X. Zhou, G. Cao, Adv. Mater. 2009, 21, 4087-4108.

[101] N. Memarian, I. Concina, A. Braga, S. M. Rozati, A. Vomiero, G. Sberveglieri, Angew. Chem. Int. Ed. 2011, 50, 12321-12325.

[102] A. Kay, M. Grätzel, Chem. Mater. 2002, 14, 2930-2935.

[103] H. J. Snaith, C. Ducati, Nano Lett. 2010, 10, 1259-1265.

[104] P. Docampo, P. Tiwana, N. Sakai, H. Miura, L. Herz, T. Mu-rakami, H. J. Snaith, J. Phys. Chem. C 2012, 116, 22840-22846.

[105] A. K. Chandiran, N. Tetreault, R. Humphry-Baker, F. Kessler, E. Baranoff, C. Yi, M. K. Nazeeruddin, M. Grätzel, Nano Lett. 2012, 12, 3941-3947.

[106] R. Willis, C. Olson, B. O'Regan, T. Lutz, J. Nelson, J. Durrant, J. Phys. Chem. B 2002, 106, 7605-7613.

[107] Y. Fukai, Y. Kondo, S. Mori, E. Suzuki, Electrochem. Commun. 2007, 9, 1439-1443
[108] M. Quintana, T. Edvinsson, A. Hagfeldt, G. Boschloo, J. Phys. Chem. C 2007, 111, 1035-1041.

[109] N. Tetreault, M. Grätzel, Energy Environ. Sci. 2012, 5, 8506-8516.

[110] L. Schmidt-Mende, M. Grätzel, Thin Solid Films 2006, 500, 296-301

[111] J. Melas-Kyriazi, I.-K. Ding, A. Marchioro, A. Punzi, B. Hardin, G. Burkhard, N. Tetreault, M. Grätzel, J.-E. Moser, M. McGehee, Adv. Energy Mater. 2011, 1, 407-414.

[112] J. Weickert, R. B. Dunbar, H. C. Hesse, W. Wiedemann, L. SchmidtMende, Adv. Mater. 2011, 23, 1810-1828.

[113] Q. Zhang, G. Cao, Nano Today 2011, 6, 91-109.

[114] Q. Zhang, D. Myers, J. Lan, S. A. Jenekhe, G. Cao, Phys. Chem. Chem. Phys. 2012, 14, 14982-14998.

[115] N. Tetreault, E. Horvath, T. Moehl, J. Brillet, R. Smajda, S. Bungener, N. Cai, P. Wang, S. Zakeeruddin, L. Forro, A. Magrez, M. Grätzel, ACS Nano 2010, 4, 7644-7650.

[116] O. Varghese, M. Paulose, C. Grimes, Nat. Nanotechnol. 2009, 4, 592-597.

[117] F. Sauvage, F. Di Fonzo, A. Bassi, C. Casari, V. Russo, G. Divitini, C. Ducati, C. Bottani, P. Comte, M. Grätzel, Nano Lett. 2010, 10, 2562-2567.

[118] F. D. Fonzo, C. S. Casari, V. Russo, M. F. Brunella, A. L. Bassi, C. E. Bottani, Nanotechnology 2009, 20, 015604.

[119] L. Passoni, F. Ghods, P. Docampo, A. Abrusci, J. Martí-Rujas, M. Ghidelli, G. Divitini, C. Ducati, M. Binda, S. Guarnera, A. Li Bassi, C. S. Casari, H. J. Snaith, A. Petrozza, F. Di Fonzo, ACS Nano 2013, 7, 10023-10031.

[120] I. Cho, Z. Chen, A. Forman, D. Kim, P. Rao, T. Jaramillo, X. Zheng, Nano Lett. 2011, 11, 4978-4984.

[121] F. Shao, J. Sun, L. Gao, S. Yang, J. Luo, J. Mater. Chem. 2012, 22 , $6824-6830$

[122] D. K. Roh, W. S. Chi, H. Jeon, S. J. Kim, J. H. Kim, Adv. Funct. Mater. 2014, 24, 379-386.

[123] F. Bates, G. Fredrickson, Phys. Today 1999, 52, 32-38.

[124] E. Crossland, M. Nedelcu, C. Ducati, S. Ludwigs, M. Hillmyer, U. Steiner, H. Snaith, Nano Lett. 2009, 9, 2813-2819.

[125] E. Crossland, M. Kamperman, M. Nedelcu, C. Ducati, U. Wies-ner, D.-M. Smilgies, G. Toombes, M. Hillmyer, S. Ludwigs, U. Steiner, H. Snaith, Nano Lett. 2009, 9, 2807-2812.

[126] P. Yang, D. Zhao, D. Margolese, B. Chmelka, G. Stucky, Nature 1998, 396, 152-155.

[127] S. Guldin, P. Docampo, M. Stefik, G. Kamita, U. Wiesner, H. Snaith, U. Steiner, Small 2012, 8, 432-440.

[128] P. Docampo, M. Stefik, S. Guldin, N. Yufa, R. Gunning, U. Wiesner, U. Steiner, H. Snaith, Adv. Energy Mater. 2012, 2, 676-682.

[129] C.-Y. Cho, J. H. Moon, Adv. Mater. 2011, 23, 2971-2975.

[130] S. K. Karuturi, J. Luo, C. Cheng, L. Liu, L. T. Su, A. I. Y. Tok, H. J. Fan, Adv. Mater. 2012, 24, 4157-4162.

[131] X. Dang, H. Yi, M.-H. Ham, J. Qi, D. S. Yun, R. Ladewski, M. S. Strano, P. T. Hammond, A. M. Belcher, Nat. Nanotechnol. 2011, 6, 377-384.

[132] A. B. F. Martinson, J. W. Elam, J. Liu, M. J. Pellin, T. J. Marks, J. T. Hupp, Nano Lett. 2008, 8, 2862-2866.

[133] N. Tetreault, E. Arsenault, L.-P. Heiniger, N. Soheilnia, J. Bril-let, T. Moehl, S. Zakeeruddin, G. A. Ozin, M. Grätzel, Nano Lett. 2011, $11,4579-4584$

[134] C. Xu, J. Wu, U. V. Desai, D. Gao, Nano Lett. 2012, 12, 2420-2424.

[135] K. Zhu, N. Neale, A. Miedaner, A. Frank, Nano Lett. 2007, 7, 69-74.

[136] K. Zhu, N. Neale, A. Halverson, J. Kim, A. Frank, J. Phys. Chem. C 2010, 114, 13433-13441.

[137] P. Docampo, A. Ivaturi, R. Gunning, S. Diefenbach, J. Kirkpatrick, C. M. Palumbiny, V. Sivaram, H. Geaney, L. Schmidt-Mende, M. E. Welland, H. J. Snaith, J. Mater. Chem. A 2013, 1, 12088-12095.

[138] G. Boschloo, A. Hagfeldt, Acc. Chem. Res. 2009, 42, 1819-1826. 
[139] H. J. Snaith, M. Grätzel, Adv. Mater. 2007, 19, 3643-3647.

[140] J. Kruger, R. Plass, M. Grätzel, P. J. Cameron, L. M. Peter, J. Phys. Chem. B 2003, 107, 7536-7539.

[141] L. Forro, O. Chauvet, D. Emin, L. Zuppiroli, H. Berger, F. Levy, J. Appl. Phys. 1994, 75, 633-635.

[142] J. Bisquert, J. Phys. Chem. B 2004, 108, 2323-2332.

[143] L. Dloczik, O. Ileperuma, I. Lauermann, L. Peter, E. Ponomarev, G. Redmond, N. Shaw, I. Uhlendorf, J. Phys. Chem. B 1997, 101, 10281-10289.

[144] J. van de Lagemaat, K. Zhu, K. Benkstein, A. Frank, Inorg. Chim. Acta. 2008, 361, 620-626

[145] S. Guldin, S. Hüttner, P. Tiwana, M. Orilall, B. Ülgüt, M. Stefik, P. Docampo, M. Kolle, G. Divitini, C. Ducati, S. Redfern, H. Snaith, U. Wiesner, D. Eder, U. Steiner, Energy Environ. Sci. 2011, 4, 225-233.

[146] P. Docampo, S. Guldin, U. Steiner, H. Snaith, J. Phys. Chem. Lett. 2013, 4, 698-703.

[147] N. Kopidakis, K. D. Benkstein, J. van de Lagemaat, A. J. Frank, J. Phys. Chem. B 2003, 107, 11307-11315.

[148] M. Law, L. Greene, J. Johnson, R. Saykally, P. Yang, Nat. Mater. 2005, 4, 455-459.

[149] B. Liu, E. Aydil, J. Am. Chem. Soc. 2009, 131, 3985-3990.

[150] M. Adachi, Y. Murata, J. Takao, J. Jiu, M. Sakamoto, F. Wang, J. Am. Chem. Soc. 2004, 126, 14943-14949.

[151] R. Penn, J. Banfield, Geochim. Cosmochim. Acta 1999, 63, 1549-1557.

[152] B. Liu, J. E. Boercker, E. S. Aydil, Nanotechnology 2008, 19, 505604.

[153] J.-Y. Liao, B.-X. Lei, H.-Y. Chen, D.-B. Kuang, C.-Y. Su, Energy Environ. Sci. 2012, 5, 5750-5757.

[154] S. Liu, J. Yu, M. Jaroniec, Chem. Mater. 2011, 23, 4085-4093.

[155] T. Miyasaka, J. Phys. Chem. Letters 2011, 2, 262-269.

[156] W. Zhang, Y. Cheng, X. Yin, B. Liu, Macromol. Chem. Phys. 2011, 212, 15-23.

[157] S. Yanagida, Y. Yu, K. Manseki, Acc. Chem. Res. 2009, 42, 1827-1838.

[158] A. Nogueira, C. Longo, M. De Paoli, Coord. Chem. Rev. 2004, 248, $1455-1468$.

[159] L. Yang, U. B. Cappel, E. L. Unger, M. Karlsson, K. M. Karlsson, E. Gabrielsson, L. Sun, G. Boschloo, A. Hagfeldt, E. M. J. Johansson, Phys. Chem. Chem. Phys. 2012, 14, 779-789.

[160] J. Kim, J. K. Koh, B. Kim, S. H. Ahn, H. Ahn, D. Y. Ryu, J. H. Kim, E. Kim, Adv. Funct. Mater. 2011, 21, 4633-4639.

[161] W. H. Howie, F. Claeyssens, H. Miura, L. M. Peter, J. Am. Chem. Soc. 2008, 130, 1367-1375.

[162] H. J. Snaith, R. Humphry-Baker, P. Chen, I. Cesar, S. M. Zakeeruddin, M. Grätzel, Nanotechnology 2008, 19, 424003.

[163] I.-K. Ding, N. Tetreault, J. Brillet, B. E. Hardin, E. H. Smith, S. J. Rosenthal, F. Sauvage, M. Grätzel, M. D. McGehee, Adv. Funct. Mater. 2009, 19, 2431-2436.

[164] U. B. Cappel, E. A. Gibson, A. Hagfeldt, G. Boschloo, J. Phys. Chem. C 2009, 113, 6275-6281.

[165] P. Docampo, A. Hey, S. Guldin, R. Gunning, U. Steiner, H. J. Snaith, Adv. Funct. Mater. 2012, 22, 5010-5019.

[166] J. Xia, N. Masaki, M. Lira-Cantu, Y. Kim, K. Jiang, S. Yanagida, J. Am. Chem. Soc. 2008, 130, 1258-1263.

[167] X. Liu, W. Zhang, S. Uchida, L. Cai, B. Liu, S. Ramakrishna, Adv. Mater. 2010, 22, E150-E155.

[168] D. Poplavskyy, J. Nelson, J. Appl. Phys. 2003, 93, 341-346.

[169] F. Fabregat-Santiago, J. Bisquert, L. Cevey, P. Chen, M. Wang, S. M. Zakeeruddin, M. Grätzel, J. Am. Chem. Soc. 2009, 131, 558-562.

[170] K. Murakoshi, R. Kogure, Y. Wada, S. Yanagida, Sol. Energy Mater. Sol. Cells 1998, 55, 113-125.

[171] G. Sadoughi, V. Sivaram, R. Gunning, P. Docampo, I. Bruder, N. Pschirer, A. Irajizad, H. J. Snaith, Phys. Chem. Chem. Phys. 2013, 15, 2075-2080.
[172] W. Zhang, R. Zhu, F. Li, Q. Wang, B. Liu, J. Phys. Chem. C 2011, 115, 7038-7043.

[173] C. Goh, S. R. Scully, M. D. McGehee, J. Appl. Phys. 2007, 101 114503.

[174] R. Zhu, C.-Y. Jiang, B. Liu, S. Ramakrishna, Adv. Mater. 2009, 21, 994

[175] E. V. Canesi, M. Binda, A. Abate, S. Guarnera, L. Moretti, V. D'Innocenzo, R. S. S. Kumar, C. Bertarelli, A. Abrusci, H. Snaith, A. Calloni, A. Brambilla, F. Ciccacci, S. Aghion, F. Moia, R. Ferragut, C. Melis, G. Malloci, A. Mattoni, G. Lanzani, A. Petrozza, Energy Environ. Sci. 2012, 5, 9068-9076.

[176] H. J. Snaith, Energy Environ. Sci. 2012, 5, 6513-6520.

[177] J. Kruger, R. Plass, L. Cevey, M. Piccirelli, M. Grätzel, U. Bach, Appl. Phys. Lett. 2001, 79, 2085-2087.

[178] H. J. Snaith, M. Grätzel, Appl. Phys. Lett. 2006, 89, 262114.

[179] A. Abate, T. Leijtens, S. Pathak, J. Teuscher, R. Avolio, M. E. Errico, J. Kirkpatrik, J. M. Ball, P. Docampo, I. McPherson, H. J. Snaith, Phys. Chem. Chem. Phys. 2013, 15, 2572-2579.

[180] U. B. Cappel, T. Daeneke, U. Bach, Nano Lett. 2012, 12, 4925-4931.

[181] S. Fantacci, F. De Angelis, M. K. Nazeeruddin, M. Grätzel, J. Phys. Chem. C 2011, 115, 23126-23133.

[182] Q. Yu, Y. Wang, Z. Yi, N. Zu, J. Zhang, M. Zhang, P. Wang, ACS Nano 2010, 4, 6032-6038.

[183] G. Boschloo, L. Haggman, A. Hagfeldt, J. Phys. Chem. B 2006, 110, 13144-13150.

[184] D. Kuang, C. Klein, H. Snaith, J. Moser, R. Humphry-Baker, P. Comte, S. Zakeeruddin, M. Grätzel, Nano Lett. 2006, 6 769-773.

[185] J. Burschka, F. Kessler, M. K. Nazeeruddin, M. Grätzel, Chem Mater. 2013, 25, 2986-2990.

[186] A. Abate, D. J. Hollman, J. Teuscher, S. Pathak, R. Avolio, G. D'Errico, G. Vitiello, S. Fantacci, H. J. Snaith, J. Am. Chem. Soc. 2013, 135, 13538-13548.

[187] C. T. Weisspfennig, M. M. Lee, J. Teuscher, P. Docampo, S. D. Stranks, H. J. Joyce, H. Bergmann, I. Bruder, D. V. Kondratuk, M. B. Johnston, H. J. Snaith, L. M. Herz, J. Phys. Chem. C 2013 117, 19850-19858.

[188] M. D. Brown, T. Suteewong, R. S. S. Kumar, V. D'Innocenzo, A. Petrozza, M. M. Lee, U. Wiesner, H. J. Snaith, Nano Lett. 2011 11, 438-445.

[189] L. Schmidt-Mende, U. Bach, R. Humphry-Baker, T. Horiuchi, H. Miura, S. Ito, S. Uchida, M. Grätzel, Adv. Mater. 2005, 17, 813.

[190] G. Y. Margulis, B. E. Hardin, I.-K. Ding, E. T. Hoke, M. D. McGehee, Adv. Energy Mater. 2013, 3, 959-966.

[191] I. Kaiser, K. Ernst, C. Fischer, R. Konenkamp, C. Rost, I. Sieber, M. Lux-Steiner, Sol. Energy Mater. Sol. Cells 2001, 67, 89-96.

[192] M. Nanu, J. Schoonman, A. Goossens, Adv. Funct. Mater. 2005, 15 95-100.

[193] R. Plass, S. Pelet, J. Krueger, M. Grätzel, U. Bach, J. Phys. Chem. B 2002, 106, 7578-7580.

[194] W. Yu, L. Qu, W. Guo, X. Peng, Chem. Mater. 2003, 15, 2854-2860.

[195] W. Huynh, J. Dittmer, A. Alivisatos, Science 2002, 295, 2425-2427.

[196] R. Vogel, K. Pohl, H. Weller, Chem. Phys. Lett. 1990, 174, 241-246.

[197] A. Alivisatos, Science 1996, 271, 933-937.

[198] A. H. Ip, S. M. Thon, S. Hoogland, O. Voznyy, D. Zhitomirsky, R. Debnath, L. Levina, L. R. Rollny, G. H. Carey, A. Fischer, K. W. Kemp, I. J. Kramer, Z. Ning, A. J. Labelle, K. W. Chou, A. Amassian, E. H. Sargent, Nat. Nanotechnol. 2012, 7, 577-582.

[199] J. A. Chang, S. H. Im, Y. H. Lee, H.-j. Kim, C. S. Lim, J. H. Heo, S. I. Seok, Nano Lett. 2012, 12, 1863-1867.

[200] J. A. Chang, J. H. Rhee, S. H. Im, Y. H. Lee, H.-j. Kim, S. I. Seok M. K. Nazeeruddin, M. Grätzel, Nano Lett. 2010, 10, 2609-2612.

[201] R. Schaller, V. Klimov, Phys. Rev. Lett. 2004, 92, 186601.

[202] R. Vogel, P. Hoyer, H. Weller, J. Phys. Chem. 1994, 98, 3183-3188.

[203] A. Zaban, O. Micic, B. Gregg, A. Nozik, Langmuir 1998, 14, 3153-3156. 
[204] S. Hotchandani, P. Kamat, J. Phys. Chem. 1992, 96, 6834-6839.

[205] E. Edri, E. Rabinovich, O. Niitsoo, H. Cohen, T. Bendikov, G. Hodes, J. Phys. Chem. C 2010, 114, 13092-13097.

[206] M. Shalom, S. Dor, S. Ruhle, L. Grinis, A. Zaban, J. Phys.Chem. C 2009, 113, 3895-3898.

[207] L. J. Diguna, Q. Shen, J. Kobayashi, T. Toyoda, Appl. Phys. Lett. 2007, 91, 023116

[208] O. Niitsoo, S. K. Sarkar, C. Pejoux, S. Ruhle, D. Cahen, G. Hodes, J. Photochem. Photobiol., A 2006, 181, 306-313.

[209] H. Lee, M. Wang, P. Chen, D. R. Gamelin, S. M. Zakeeruddin, M. Grätzel, M. K. Nazeeruddin, Nano Lett. 2009, 9, 4221-4227.

[210] F. T. F. O'Mahony, T. Lutz, N. Guijarro, R. Gomez, S. A. Haque, Energy Environ. Sci. 2012, 5, 9760-9764.

[211] I. Mora-Sero, S. Gimenez, F. Fabregat-Santiago, R. Gomez, Q. Shen, T. Toyoda, J. Bisquert, Acc. Chem. Res. 2009, 42, 1848-1857.

[212] A. Darga, D. Mencaraglia, C. Longeaud, T. J. Savenije, B. O'Regan, S. Bourdais, T. Muto, B. Delatouche, G. Dennler, J. Phys. Chem. C 2013, 117, 20525-20530.

[213] G. Xing, N. Mathews, S. Sun, S. S. Lim, Y. M. Lam, M. Grätzel, S. Mhaisalkar, T. C. Sum, Science 2013, 342, 344-347.

[214] S. D. Stranks, G. E. Eperon, G. Grancini, C. Menelaou, M. J. P. Alcocer, T. Leijtens, L. M. Herz, A. Petrozza, H. J. Snaith, Science 2013, 342, 341-344.

[215] M. M. Lee, J. Teuscher, T. Miyasaka, T. N. Murakami, H. J. Snaith, Science 2012, 338, 643-647.

[216] A. Abrusci, S. D. Stranks, P. Docampo, H.-L. Yip, A. K. Y. Jen, H. J. Snaith, Nano Lett. 2013, 13, 3124-3128.

[217] G. E. Eperon, V. M. Burlakov, P. Docampo, A. Goriely, H. J. Snaith, Adv. Funct. Mater. 2014, 24, 151-157.

[218] J. M. Ball, M. M. Lee, A. Hey, H. Snaith, Energy Environ. Sci. 2013, $6,1739-1743$

[219] D. Bi, L. Haggman, G. Boschloo, L. Yang, E. M. J. Johansson, A. Hagfeldt, R. Soc. Chem. Adv. 2013, 3, 18762-18766.

[220] M. Liu, M. B. Johnston, H. J. Snaith, Nature 2013, 501, 395-398.

[221] G. Hodes, J. Phys. Chem. C 2008, 112, 17778-17787.

[222] I. Mora-Sero, J. Bisquert, J. Phys. Chem. Lett. 2010, 1, 3046-3052.

[223] J.-H. Im, C.-R. Lee, J.-W. Lee, S.-W. Park, N.-G. Park, Nanoscale 2011, 3, 4088-4093.

[224] A. Kojima, K. Teshima, Y. Shirai, T. Miyasaka, J. Am. Chem.Soc. 2009, 131, 6050-6051

[225] J. Tang, K. W. Kemp, S. Hoogland, K. S. Jeong, H. Liu, L. Levina, M. Furukawa, X. Wang, R. Debnath, D. Cha, K. W. Chou, A. Fischer, A. Amassian, J. B. Asbury, E. H. Sargent, Nat. Mater. 2011, 10, 765-771.

[226] T. Muto, G. Larramona, G. Dennler, Appl. Phys. Express 2013, 6, 072301.

[227] H.-S. Kim, C.-R. Lee, J.-H. Im, K.-B. Lee, T. Moehl, A. Marchioro, S.-J. Moon, R. Humphry-Baker, J.-H. Yum, J. E. Moser, Sci. Rep. 2012, 2, 591 .

[228] M. Wang, S.-J. Moon, M. Xu, K. Chittibabu, P. Wang, N.-L. Cevey-Ha, R. Humphry-Baker, S. M. Zakeeruddin, M. Grätzel, Small 2010, 6, 319-324.

[229] C.-Y. Chen, M. Wang, J.-Y. Li, N. Pootrakulchote, L. Al-ibabaei, C.-h. Ngoc-le, J.-D. Decoppet, J.-H. Tsai, C. Grätzel, C.-G. Wu, S. M. Zakeeruddin, M. Grätzel, ACS Nano 2009, 3, 3103-3109.

[230] O. Kohle, M. Grätzel, A. Meyer, T. Meyer, Adv. Mater. 1997, 9, 904.

[231] Y. Tachibana, J. Moser, M. Grätzel, D. Klug, J. Durrant, J. Phys. Chem. 1996, 100, 20056-20062.

[232] R. Grunwald, H. Tributsch, J. Phys. Chem. B 1997, 101, 2564-2575.
[233] H. Tributsch, Coord. Chem. Rev. 2004, 248, 1511-1530.

[234] T. Leijtens, G. E. Eperon, S. Pathak, A. Abate, M. M. Lee, H. J. Snaith, Nat. Commun. 2013, 4, 2885.

[235] D. C. Cronemeyer, Phys. Rev. 1959, 113, 1222-1226.

[236] J. Bisquert, F. Fabregat-Santiago, I. Mora-Sero, G. Garcia-Belmonte, E. M. Barea, E. Palomares, Inorg. Chim. Acta. 2008, 361, 684-698.

[237] M. A. Henderson, W. S. Epling, C. L. Perkins, C. H. Peden, U. Diebold, J. Phys. Chem. B 1999, 103, 5328-5337.

[238] G. Lu, A. Linsebigler, J. John, T. Yates, J. Chem. Phys 1995, 102, 4657-4662.

[239] K. Schwanitz, U. Weiler, R. Hunger, T. Mayer, W. Jaegermann, J. Phys. Chem. C 2006, 111, 849-854.

[240] K. Schwanitz, E. Mankel, R. Hunger, T. Mayer, W. Jaegermann, Chimia 2007, 61, 796-800.

[241] C. L. Olson, J. Nelson, M. S. Islam, J. Phys. Chem. B 2006, 110, 9995-10001.

[242] G. Munuera, V. Rives-Arnau, A. Saucedo, J. Chem. Soc., Faraday Trans. 1 1979, 75, 736-747.

[243] J. Weidmann, T. Dittrich, E. Konstantinova, I. Lauermann, I. Uhlendorf, F. Koch, Sol. Energy Mater. Sol. Cells 1999, 56, 153-165.

[244] Y. Kim, B. J. Yoo, R. Vittal, Y. Lee, N.-G. Park, K.-J. Kim, J. Power Sources 2008, 175, 914-919.

[245] J. Meyer, P. Goerrn, F. Bertram, S. Hamwi, T. Winkler, H.-H. Johannes, T. Weimann, P. Hinze, T. Riedl, W. Kowalsky, Adv. Mater. 2009, 21, 1845

[246] M. O. Reese, A. J. Morfa, M. S. White, N. Kopidakis, S. E. Shaheen, G. Rumbles, D. S. Ginley, Sol. Energy Mater. Sol. Cells 2008, 92, 746-752.

[247] J. H. Noh, S. H. Im, J. H. Heo, T. N. Mandal, S. I. Seok, Nano Lett. 2013, 13, 1764-1769.

[248] S. K. Pathak, A. Abate, T. Leijtens, D. J. Hollman, J. Teuscher, L. Pazos, P. Docampo, U. Steiner, H. J. Snaith, Adv. Energy Mater. 2014, DOI: 10.1002/aenm.201301667.

[249] A. Hinsch, J. M. Kroon, R. Kern, I. Uhlendorf, J. Holzbock, A. Meyer, J. Ferber, Prog. Photovoltaics 2001, 9, 425-438.

[250] P. Sommeling, M. Spath, H. Smit, N. Bakker, J. Kroon, J. Photochem. Photobiol., A 2004, 164, 137-144.

[251] S. Yu, S. Ahmadi, C. Sun, P. Palmgren, F. Hennies, M. Zuleta, M. Gothelid, J. Phys. Chem. C 2010, 114, 2315-2320.

[252] P. Wang, S. Zakeeruddin, J. Moser, M. Grätzel, J. Phys. Chem. B 2003, 107, 13280-13285.

[253] Y. Bai, Y. Cao, J. Zhang, M. Wang, R. Li, P. Wang, S. M. Zakeeruddin, M. Grätzel, Nat. Mater. 2008, 7, 626-630.

[254] M. K. Kashif, M. Nippe, N. W. Duffy, C. M. Forsyth, C. J. Chang, J. R. Long, L. Spiccia, U. Bach, Angew. Chem. Int. Ed. 2013, 52, $5527-5531$.

[255] P. Docampo, H. J. Snaith, Nanotechnology 2011, 22, 225403

[256] F. C. Krebs, H. Spanggaard, Chem. Mater. 2005, 17, 5235-5237.

[257] M. Jorgensen, K. Norrman, F. C. Krebs, Sol. Energy Mater. Sol. Cells 2008, 92, 686-714.

[258] C. J. Brabec, S. Gowrisanker, J. J. Halls, D. Laird, S. Jia, S. P. Williams, Adv. Mater. 2010, 22, 3839-3856.

[259] C. H. Peters, I. T. Sachs-Quintana, W. R. Mateker, T. Heumueller, J. Rivnay, R. Noriega, Z. M. Beiley, E. T. Hoke, A. Salleo, M. D. McGehee, Adv. Mater. 2012, 24, 663-668.

[260] C. H. Peters, I. T. Sachs-Quintana, J. P. Kastrop, S. Beaupre, M. Leclerc, M. D. McGehee, Adv. Energy Mater. 2011, 1, 491-494.

[261] S. Guldin, Inorganic Nanoarchitectures by Organic Self-Assembly Inorganic Nanoarchitectures by Organic Self-Assembly, $7^{\text {st }} E d$., Springer Theses, Springer Int. Publishing, Switzerland, 2013. 